\title{
Asia's materialists: Reconciling collectivism and materialism
}

\author{
Sandra Awanis ${ }^{1}$, \\ Bodo B Schlegelmilch ${ }^{2,3}$ and \\ Charles Chi Cui ${ }^{4}$ \\ ${ }^{1}$ Lancaster University Management School, \\ Bailrigg, Lancaster LA1 4YX, UK; ${ }^{2}$ WU Vienna, \\ Vienna, Austria; ${ }^{3}$ Lingnan University College, Sun \\ Yat-sen University, Guangzhou, China; ${ }^{4}$ Alliance \\ Manchester Business School, University of \\ Manchester, Manchester, UK \\ Correspondence: \\ $S$ Awanis, Lancaster University Management \\ School, Bailrigg, Lancaster LA1 4YX, UK. \\ Tel: (+44) 1524 10529; \\ e-mail: s.awanis@lancaster.ac.uk
}

\begin{abstract}
Materialism has an ugly face. The dominant view of materialism regards materialists as self-prioritizing individuals who oppose collective and prosocial goals in favor of a lifestyle led by money, possessions, and status. The present research argues that there is a side of materialism that is concerned with collective-oriented interests. We examine the nature and consequences of collective-oriented materialism - the belief system that ascribes importance to possessions for their symbolic and signaling capacities to construct desirable social attributes. Drawing from cultural and consumer theories, we find considerable support that materialists espouse a collective-oriented quality to an otherwise self-oriented interest towards possessions.
\end{abstract}

Journal of International Business Studies (2017) 48, 964-99l.

doi: | 0.1 057/s4 I 267-017-0096-6

Keywords: materialism; values; Asia; cultural values; conspicuous consumption; multidimensional scaling; moderation analysis

The online version of this article is available Open Access.

\section{INTRODUCTION}

Materialism, defined as a value system that assigns primacy to possessions and the social image they project (Bauer, Wilkie, Kim, \& Bodenhausen, 2012), is often seen as a social problem that plagues contemporary society. Materialists are frequently stigmatized as selfish individuals who "crowd out" social relationships in favor of a lifestyle led by the acquisition of money, material possessions, and status (Dittmar, Bond, Hurst, \& Kasser, 2014; Pieters, 2013). Such self-oriented view of materialism, however, risks oversimplification in assuming that highly materialistic consumers are inherently uninterested in collective and prosocial goals.

The original concept of materialism emphasizes the acquisition of money, possessions, and status for the sole purpose of one's selfenhancement and preservation (Belk, 1985; Richins \& Dawson, 1992). This view paints materialists as those who reject collectiveoriented values such as moderation, self-sacrifice, and building interpersonal relationships in favor of less meaningful relationships with possessions (Bauer et al., 2012; Burroughs \& Rindfleisch, 2002; Van Boven, Campbell, \& Gilovich, 2010). As Burroughs and Rindfleisch's (2002) study shows, relative to the larger human
Received: 11 December 2015

Revised: 30 June 2017

Accepted: 16 July 2017

Online publication date: 29 August 2017 
value system, materialism in the United States is closely associated with self-oriented values and diametrically opposed to others-oriented values. However, this finding raises an issue of generality. Do consumers consistently maintain a conflicting value perspective of material and collective values?

Materialism may be more intertwined with collective-oriented values than previously suggested. As Cleveland (2015: 147) observed: "a visit to Nanjing Road (Shanghai), Causeway Bay (Hong Kong), the Ginza (Tokyo), the Dubai Mall (the world's largest), or for that matter, l'avenue des Champs-Élyssés (Paris, where the upscale shops of Cartier, etc. are thronged with East Asian and Middle-Eastern shoppers) will persuade any skeptic that materialistic passion has been enthusiastically embraced by collectivist peoples."

Indeed, Markus and Kitayama (1991) indicate that materialistic behavior appears to align with collective-oriented values among those who uphold an interdependent self-construal. This explains why consumers from collectivistic societies in the East are surpassing their Western counterparts in terms of materialistic disposition and consumption (Ger \& Belk, 1990).

Such apparent reconciliation between material and collective values and goals may seem unique to those who were socialized within the collectivistic cultural framework. Collectivists identify with their group membership as a central aspect of identity and develop personal values that reflect the goals of the collective, such as sacrificing self-interest for collective interests and maintaining harmonious relationships with others (Oyserman, Coon, \& Kemmelmeier, 2002). Thus, they are likely to value material ownership and acquisitions that allow them to maintain collective interests and goals. For example, in emerging markets and among ethnic communities, people consume conspicuously (e.g., through luxury brands or imported products) to cast a positive light upon their in-groups (Cleveland \& Chang, 2009; Sharma, 2011). Collectivists also do not appear to regard material and collective goals as an apparent contradiction. For example, the Confucian traditions in East Asia regard aspirational consumption as an "exemplar of social virtues in fulfilling familial obligation" (Wong \& Ahuvia, 1998: 434). Overall, these studies suggest that collectivistic individuals may find solace in using possessions to fulfill social expectations and enact collective goals.

However, the reconciliation of material and collective values transcends beyond the collectivistic cultural boundaries. People who are socialized within an individualistic social structure also value material possessions for their capacity to fulfill collective values and goals, though their interpretation of what constitutes the collective interest may differ from those who are socialized within a collectivist culture (Markus \& Kitayama, 1991; Schwartz, 1990; Singelis, 1994). Research shows that members of collectivistic cultures maintain interpersonal collective-oriented values that encapsulate prosocial concerns for the welfare of one's in-groups and the building of harmonious relationships (Schwartz, 1990; Triandis, McCusker, \& Hui, 1990). Meanwhile, members of individualistic cultures subscribe to transcendental collective-oriented values that emphasize a broader view of the collective (e.g., equality, social justice, and spirituality) without sharply distinguishing between the in- and outgroups. As such, even individualistic consumers may engage in collective-oriented materialistic consumption, such as gift-giving, public donation, and green consumption, to signal desirable qualities of altruism and social concern (Shrum et al., 2014; Strizhakova \& Coulter, 2013). The global spread of prosocial awareness has also affected the state of international consumerism, with half of global consumers that they are willing to pay more for products and services from companies that are committed to positive social impacts (Nielsen, 2014).

However, insofar as the current domain of materialism - as manifested in the acquisition of money, possessions, and status - represents self-oriented motivations, such theoretical concept is limited in its representation of collective-oriented consumption motives. Furthermore, the body of evidence supporting the congruence of material and collective-oriented values remains scant. This research gap is surprising since extant research claims that aligning materialistic with collective interests is key to businesses and policymakers that seek to promote prosocial values in an increasingly materialistic society. In redressing this research gap, the present research offers empirical support for a positive side to materialism that is concerned with collective and prosocial welfare.

The present research defines collective-oriented materialism as a belief system that values possession and its acquisitions for their symbolic capacity to grant status to oneself or others, enable compliance with social expectations, demonstrate belongingness to a desired reference group, and fulfill their perceived social responsibilities. Extant research and practice have overwhelmingly focused on the "dark side" (Mick, 1996) of materialism that builds 
on the stigmatized view of self-oriented materialists who reject collective values and goals (Bauer et al., 2012; Burroughs \& Rindfleisch, 2002; Van Boven et al., 2010). Thus, the present research contributes to theory by extending the boundary conditions of materialism, hence enriching the body of international consumer research and unsealing new channels for future research. Our emphasis on collective-oriented materialism across individualistic and collectivistic cultures also encapsulates JIBS tradition in furthering scholarly understanding of the effect of cultural values on the making of important strategic decisions (Beugelsdijk, Kostova, \& Roth, 2016; Caprar, Devinney, Kirkman, \& Caligiuri, 2015; Leung \& Morris, 2014).

Our focus, therefore, is to understand the nature and consequences of collective-oriented materialism. In doing so, we examine the cultural differences of collective-oriented materialism across collectivist and individualist societies through international research involving the US, China, India, and Thailand. Hence, the present research aims to address the following questions:

1. Can collective-oriented materialism be observed across cultures?

2. What effects does collective-oriented materialism have on consumption deliberation across cultures?

In the next section, we distinguish between the theoretical concepts of self- and collective-oriented materialism. We then offer a fine-grained analysis of collectively motivated materialism and how it relates differently to individualistic and collectivistic cultures. Next, we present a set of culture-specific hypotheses based on the aforementioned research questions. Our hypotheses encase two research objectives. First, we seek to examine the placement of material value among the broader array of important life values and evaluate whether the self-oriented view of materialism is universally applicable across societies that subscribe to individualistic and collectivistic cultural orientations. Second, we aim to examine the consequences of materialism on conspicuous consumption, and the role of culture-specific collective values in moderating this relationship. To follow, we outline the research setting, methodology, and analytical procedures employed in this study. We then provide a detailed account of the findings and discuss the theoretical and managerial implications of our work. The article closes by considering its limitations and future research directions.

\section{SELF-ORIENTED MATERIALISM}

Highly materialistic individuals regard possessions and acquisition as necessary means to achieve important goals, such as happiness, success, and desirability (Belk, 1985; Richins \& Dawson, 1992). However, research also shows that materialism is synonymous with low subjective well-being (Richins \& Dawson, 1992), reduced life satisfaction (Burroughs \& Rindfleisch, 2002), and broken interpersonal relationships (Kasser \& Ahuvia, 2002). These findings lead to the assumption that materialism encompasses self-oriented individuals who prefer to build meaningful relationships with possessions rather than with people and society at large (Burroughs \& Rindfleisch, 2002; Kasser \& Ryan, 1993). These selfish stereotypes of highly materialistic consumers effectively place materialism firmly on the "dark side" of marketing (Mick, 1996).

Burroughs and Rindfleisch's (2002) work offers an explanation for the self-oriented view of materialism. Their study of consumers from the United States showed that relative to the larger human value system, materialism is closely aligned to selforiented values and adjacent to others-oriented values. Coined as a value-conflict theory, this viewpoint argues that materialism (i.e., the value individuals place on the acquisition and possession of material objects) will always contradict collective-oriented values such as religious commitment, moderation, and self-sacrifice (Burroughs \& Rindfleisch, 2002). Thus, materialists who uphold collective-oriented values - for instance, those who maintain materialistic aspirations and philanthropic duties - are likely to experience internal value conflict that subsequently manifests in the forms of heightened psychological tension and poorer subjective well-being (Burroughs \& Rindfleisch, 2002).

As the self-oriented view of materialism dominates current understanding of materialism in practice and academia, it creates a foundation of anti-materialism campaigns that promote materialistic ideals (Burroughs et al., 2013) and overconsumption (Richins, 2011). For example, Kasser (2016) endorses a 10\% marketing tax rate and supports a ban on advertising from public places for "value pollution" (p. 595). Similarly, the World Obesity Policy and Prevention's (2008) "Sydney Principles" called for the national and transnational governing bodies to regulate cross-border commercial channels, including the Internet, cable television, and print media, to stop the spread of 
materialism from affecting the younger generation. These anti-materialism views, however, create an overwhelming tension between business and policy. Therefore, it stands to reason that an analysis of material and collective-oriented value alignment will advance current understanding and provide pointers to global business and policy on how to promote a prosocial view of materialism.

\section{COLLECTIVE-ORIENTED MATERIALISM}

The need to belong is a deep-seated and pervasive human value in interpersonal behavior (Baumeister $\&$ Leary, 1995). The notion that consumption is contingent on collectivistic motivation is also well established. For instance, consumers judge materialistic goods not only through their idiosyncratic experience and expectations, but also based on their impression of how others will evaluate the goods (Hunt, Kernan, \& Mitchell, 1996). Likewise, Puntoni and Tavassoli (2007) show that the mere presence of others can activate impression management concerns, thus prompting people to seek socially desirable cues in consumption. In line with these findings, it is reasonable to argue that materialists are equally looking to develop a social identity as do non-materialists (Cleveland, 2015; Sharma, 2011).

However, people subscribe to varying views of collective ideals. Thus, they variably acquire, adhere to, or reject aspects from each view. Brewer and Chen (2007) note that the definition of the collective varies significantly across collectivistic and individualistic cultures. Collectivistic cultures define the collective as a narrowly distinguished in-group. Here, social bonds are formed based on specific interpersonal relationships or relational networks with personalized bonds of attachment, such as family, colleagues, and hometown fellows. Thus, members of collectivist cultures subscribe to interpersonal collective values that emphasize harmonious relationships with the in-groups (e.g., family, friends, coworkers), compliance to traditions, and conformity to social norms (Schwartz, 1990). Such in-group orientation explains why collectivistic societies often show less consideration for the welfare of the out-groups (e.g., strangers) than do individualistic societies (Brewer \& Chen, 2007). Meanwhile, individualistic culture conceptualizes the collective in terms of an embodiment of a shared social category, where social bonds are based on emotional predisposition, common interests, and spiritual alignment (Brewer \& Chen, 2007). Thus, members of individualistic cultures subscribe to a much broader and transcendental (i.e., abstract) definition of the collective than their collectivistic counterparts (Schwartz, 1990). The diverging views of collective ideals necessitate a further investigation into how they may differently influence the degree of materialistic alignment with collective-oriented values across individualist/collectivist societies.

Unifying these themes, we argue that there is a side of materialism that is concerned with collectiveoriented interests, goals, and values. Specifically, we postulate that highly materialistic consumers demonstrate a stronger attraction to the social symbolism of consumption and acquisition when they believe that they can meet their collective duties (or find congruence with one's own collectivistic beliefs) through socially approved consumption. For example, parents selecting a school for their children may base their decisions on socially constructed measures such as prestige and reputation over objective measures such as the cost of school fees to demonstrate their commitment to their children's education. In a similar fashion, consumers may spend a considerable amount on highvalue, high-ticket items as social investments that can be passed down through generations to strengthen familial ties. Patek Philippe taps into such collective-oriented view of materialism through its recent advertising campaign that emphasizes the emotional bond and duty of a father to his son ("you never actually own a Patek Phillipe, you merely look after it for the next generation"). Therefore, we conceptualize collective-oriented materialism as the belief system that ascribes importance to possessions for their symbolic and signaling capacities to grant status to oneself and others, enable compliance with social expectations, demonstrate belongingness to a desired reference group, and fulfill their perceived social responsibilities.

Collective-oriented materialism emanates from an internal negotiation between the collective- and self-oriented interests in the possession and acquisition of material goods. Thus, the materialists' penchant for symbolism in material goods is likely to be determined by the degree to which they regard collective-oriented values as important. To this end, we theorize that collective-oriented materialism is expressed when collective-oriented values negatively moderate (or reduce) the strength of the materialistic appeal for the self-promotional aspect of material goods in favor of the prosocial aspects of material goods.

The definition of collective varies substantially across collectivistic and individualistic cultures 


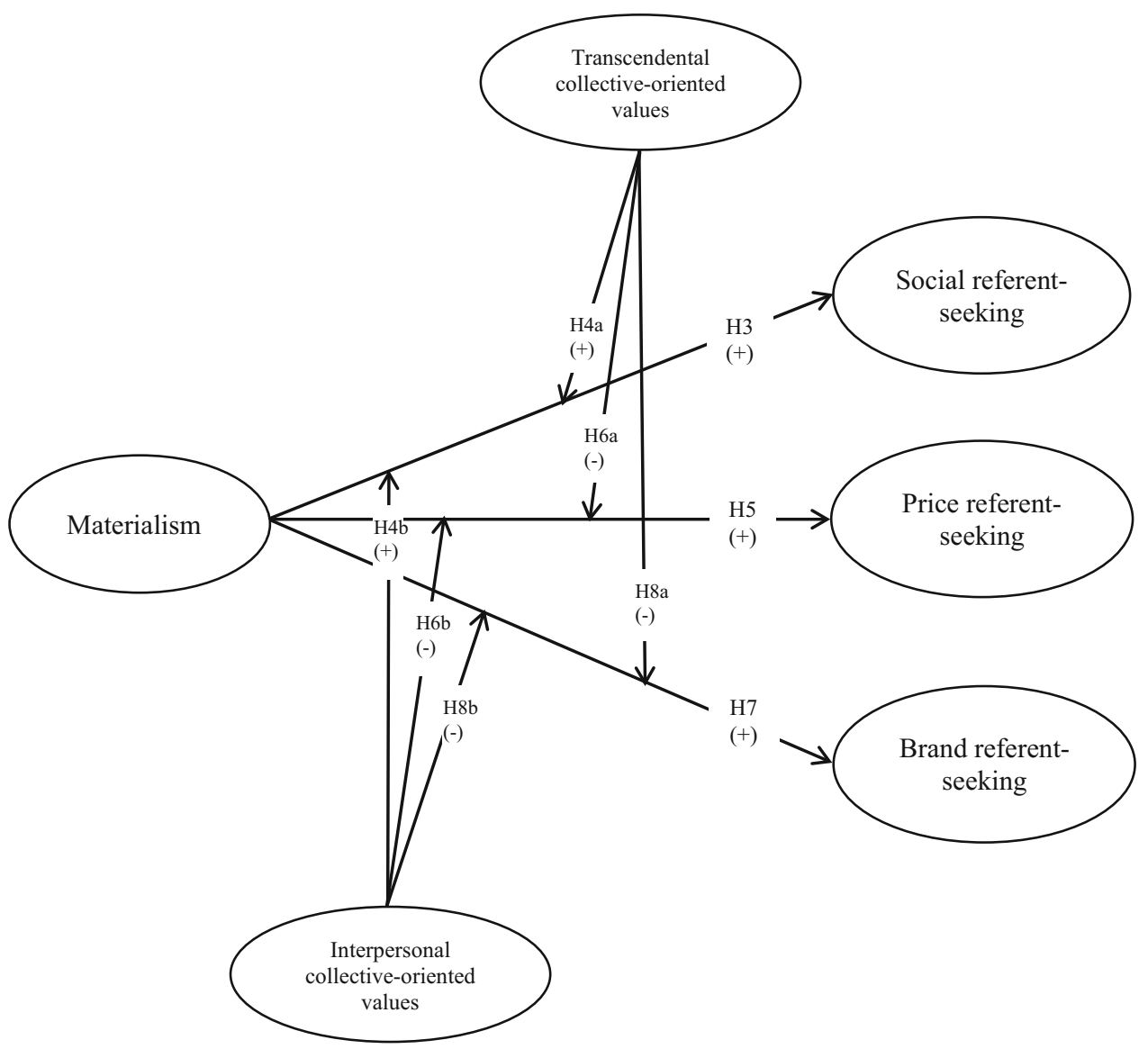

Figure 1 The conceptual model. Note: $\mathrm{H} 1$ and $\mathrm{H} 2$ are not outlined in the conceptual model. The conceptual distances between materialism and collective-oriented values are tested separately using multidimensional scaling and correlation analysis.

(Brewer \& Chen, 2007), suggesting that different cultures subscribe to different aspects of collectiveoriented values (Schwartz, 1990; Triandis, 1995). Consequently, the salient interpretation of collective beliefs in each culture is likely to influence the nature of collective-oriented materialism across its members. Our conceptual model (Figure 1) illustrates collective-oriented materialism in terms of the moderating role of interpersonal and transcendental collective values in reducing the strength of materialistic passion in conspicuous consumption, which signifies a trademark of self-oriented materialism (Belk, 1985; Richins \& Dawson, 1992).

\section{HYPOTHESIS DEVELOPMENT}

\section{Materialism and Collective Orientation}

Despite the prominence of the self-oriented view of materialism, we propose that the value conflict between material and collective-oriented values is unlikely to be generalizable to members of collectivistic cultures who show higher tolerance towards conflicting ideologies than their individualistic counterparts. A subset of collectivistic cultures encompasses those who embrace Confucian ideologies rooted in East Asia. Research examining these communities (e.g., Bagozzi, Wong, \& Yi, 1999; Peng \& Nisbett, 1999) regularly find that they are relatively comfortable with apparent contradictions and accept them as part of the natural order. For instance, Bagozzi et al. (1999) find that East Asians tend to experience positive and negative emotions in a more dialectical and holistic manner, while those from the US view positive and negative emotions as bipolar contradictions. Consequently, members of collectivistic societies may not see materialistic and collectivistic interests as conflicting ideals. For example, Wong, Rindfleisch, and Burroughs (2003) identified distinct cultural bias within Richins and Dawson's (1992) materialism scale, such that people from East Asian backgrounds are less likely to distinguish between 
materialistic and non-materialistic statements than their American counterparts.

Indeed, the Western philosophical traditions of American culture perceive contradictions as unacceptable and thus draw a sharp divide between materialism and anti-materialism (Bagozzi et al., 1999). For example, the Anglican view, "the love of money is the root of all evil", dictates that material acquisition distracts one from the true purpose of being, that is, the fulfillment of collective and religious values (Veer \& Shankar, 2011). As such, the anti-materialism view of major religions has rendered materialistic passion a vice or an unacceptable moral transgression (Cleveland, Laroche, \& Papadopoulos, 2009). Such belief explains how the individualistic culture breeds a type of materialism that is duly opposed to collective-oriented values. As collective socialization and programming sharpen people's ability to balance materialism and collective value pursuits, collectivistic consumers are thus likely to experience value conflict to a much lesser degree than those who are socialized within an individualist social structure.

The congruence between materialism and collective-oriented values in collectivistic culture is further evidenced through commonly encountered collectivistic social norms that include face-saving, conformity, and social support for high ambition (Güngör, Karasawa, Boiger, Dinçer, \& Mesquita, 2014; Hamamura, 2012; Park, 1998; Wong \& Ahuvia, 1998). Face-saving refers to a positive image of self that is affirmed through interaction with others (Ho, 1976). Face-oriented consumers go out of their way to ensure that their consumption experiences do not cause a loss of face since the shame will have a reverberating effect beyond one's self-concept to include family, friends, and even coworkers' social pride. For example, the gift-giving tradition in East Asia dictates that a gift purchase should take into consideration the gift receiver's financial position to prevent both parties from losing face when the receiver is unable to reciprocate with a similar value gift. Consequently, consumers tend to opt for materialistic purchases that are safe and appropriate for maintaining good social interaction (Bao, Zhou, \& Su, 2003; Chan, Wan, \& Sin, 2009; Liao \& Wang, 2009).

Conformity, defined as the accommodation of one's behavior to match the expectations of significant others, is another cultural hallmark of collectivist societies (Cialdini \& Goldstein, 2004; Markus
\& Kitayama, 1991). Collectivists value conformity because it offers a safe zone for people to "fit in" and construct their relational identity (Güngör et al., 2014). Thus, their materialistic purchases tend to mirror and reciprocate the purchase decisions of those they regard as important.

Similarly, collectivists demonstrate a strong social support for ambition towards members of their ingroups. The desire for social mobility is driven by many collectivistic nations' impoverished pasts. Accordingly, aspirational consumption in forms of luxury and conspicuous purchases is often congratulated, celebrated, and admired by the ingroup, rather than seen as an unnecessary extravagance (Ahuvia \& Wong, 1995). Collectivistic societies also tend to associate an individual's success as the family's success (likewise, an individual's failure is also seen as a reflection of the family). Thus, collectivists who seek to measure and demonstrate success through material possessions and consumptions are likely to find support from their in-groups. In contrast, financial success aspiration in individualist culture tends to be associated with material competitiveness and "keeping up with the Joneses" manner of social comparison. Consequently, in an individualist culture, a materialistic means of demonstrating success is likely to be construed as a self-promotion behavior (Kasser \& Ryan, 1993).

In sum, the collectivistic culture's tolerance towards conflicting ideas and the social norms that place emphasis on interpersonal relationships suggest that these societies do not necessarily regard materialism as a contradicting value system to their collective ideals (Shrum et al., 2013). Consequently, we hypothesize that consumers from the collectivistic cultures in our study (i.e., China, India, and Thailand) will perceive a narrower conceptual distance between materialism and collective-oriented values than those from the individualistic culture (i.e., the US). Thus, we expect that materialism will be positively correlated with collective-oriented values across members of collectivistic cultures. Conversely, following Burroughs and Rindfleisch's (2002) findings, we hypothesize an inverse relationship between materialism and collective-oriented values among members of individualistic cultures.

Hypothesis 1: In individualistic cultures, materialism is negatively associated with collective-oriented values. 
Hypothesis 2: In collectivistic cultures, materialism is positively associated with collectiveoriented values.

\section{Materialism and Conspicuous Consumption}

Conspicuous consumption refers to the purchase and public display of purchases to communicate the meaning of who one is (Belk, 1988; Griskevicius, Tybur, Sundie, Cialdini, Miller, \& Kenrick, 2007; Lee \& Shrum, 2012). While conspicuous consumption does not de facto indicate expressions of materialism, conspicuous purchases are naturally alluring for materialists for its signaling function (Shrum et al., 2013, 2014). Extant research argues that self-oriented materialists use conspicuous consumption for self-signaling purposes and to deliberately cause envy - such as through consumption of goods that demonstrate wealth or social power (Belk, 1985; Richins \& Dawson, 1992). However, conspicuous consumption also grants others-signaling properties, which allow people to signal desirable social attributes through means of consumption (Shrum et al., 2013). For example, people may perform altruistic acts in public (e.g., charity donation and sharing) to signal prosocial qualities such as kindness and generosity (Shrum et al., 2014). Thus, materialists from collectivistic societies may carry out conspicuous consumption to elevate the social standing of their relevant ingroups. For example, the consumption of imported luxury brands among ethnic consumers from emerging markets is often motivated by a need to reflect one's bond and commitment to important reference groups, such as family, friends, and colleagues (Cleveland, 2015; Sharma, 2011).

Materialists are meaning seekers who employ heuristics to inform their inferences (Hunt et al., 1996). Thus, when evaluating a marketing message, materialists focus more on the goods' symbolic meaning, rather than their utility. Materialistic consumers' attraction to heuristics is driven and informed by referents, defined as external sources of meanings that shape a consumer's inferences and belief formation to inform choice decisions (Klein \& Oglethorpe, 1984). Materialists compare goods and their associated meanings with a referent to determine the fit between the material goods with their self-concept and projected identity. By looking at the referents as sources of meanings in conspicuous consumption, we attempt to derive a better understanding of the typology of meanings that are valuable to materialists, and how collective-oriented values may moderate such attraction. Our review of the extant literature suggests that materialistic consumers fixate on three forms of referents to inform and drive meanings into their conspicuous consumption: social, price, and brand referents. In the following sections, we examine materialists' attraction towards these referents through the lenses of distinctiveness (Brewer, 1991), scarcity (Verhallen \& Robben, 1994), and insecurity (Rindfleisch, Burroughs, \& Wong, 2009) theories.

\section{Social Referent and the Distinctiveness Hypothesis}

Social referents refer to social groups that individuals wish to be associated with, the views and opinions of whom inject meanings into material goods that are instrumental in setting normative standards for self-appraisal (Bearden \& Etzel, 1982; Ryan, 1982). Humans universally share the desire to construct a social identity that is either similar or unique to one's reference group (Brewer, 1991; Leonardelli, Pickett, \& Brewer, 2010; Vignoles, Chryssochoou, \& Breakwell, 2000). During a quest to construct a social identity, individuals face two competing drives: the need for differentiation and assimilation. The need for differentiation refers to an individual pursuit to establish and maintain an identity that is differentiated from others (Tian, Bearden, \& Hunter, 2001; Wong et al., 2011). The need for assimilation is defined as an individual pursuit to foster feelings of closeness and acceptance (Wong et al., 2011). Optimal distinctiveness theory (Brewer, 1991) postulates that individuals seek to resolve the tension between these opposing needs by seeking the desired level of distinctiveness from their reference group.

Individuals looking for assimilation may forge connections with a particular subculture by publicly emulating forms of consumption that are relevant and meaningful to the reference group, such as consuming organic food from Whole Foods to be part of the healthy-eating movement, or designing and building high-end gaming PC to attain approval from the gaming community. Equally, consumers may consume products to feel different from others, for example, by choosing personalized, unusual, or innovative products that few others in one's social circle own (Gierl \& Huettl, 2010; Ruvio, 2008). Materialists engage in conspicuous consumption to establish an optimal sense of social identity. In this article, we propose that the degree to which materialists seek social referents to validate their conspicuous consumption depends on the extent to which their cultural orientations prioritize the needs for differentiation and assimilation. 
The self-oriented view of materialism contends that highly materialistic individuals are likely to pursue conspicuous consumption to engage in selfpromotion (Burroughs \& Rindfleisch, 2002; Kim \& Kramer, 2015). Thus, consumers who subscribe to self-oriented values are likely to consume conspicuously to promote status, popularity, and leadership (Kim \& Kramer, 2015). Such motive reflects a need for distinctiveness. Therefore, based on the dominant view of self-oriented materialism, we expect to see a positive relationship between materialism and social referent-seeking.

However, we also expect that collective-oriented values will reduce the need for distinctiveness and increase the salience of the need to assimilate with the reference group. This is because those who uphold collective-oriented values are predisposed, through means of socialization and enculturation, to align their thinking and behavior with those of their respected social groups (e.g., family, community, religious group). Consequently, those who subscribe to collective-oriented values are likely to regard social referents - such as familial or peer-based referents, opinion leaders, and aspiration groups - in high esteem as they represent the key reference point that validates the acceptance of one's conspicuous consumption. Indeed, socially approved consumption signals assimilation and positive social commitment, which allows consumers to avoid social sanction and criticism (Escalas \& Bettman, 2005) and substantiate their collective-oriented values. Due to the greater and more complex role of social referents in ensuring that consumption meets social expectations, we hypothesize that collective-oriented values will enhance the materialists' pursuit of social referent-seeking during a conspicuous consumption deliberation.

Moreover, cultural differences can affect the balance between the opposing needs for differentiation and assimilation, so that the equilibrium occurs at a lower degree of distinctiveness among collectivistic than individualistic consumers (Triandis, 1995; Vignoles et al., 2000). In collectivistic cultures, where interpersonal values are salient, consumers are deeply ingrained to prioritize assimilation and maintenance of harmonious relationships over individual distinctiveness. Meanwhile, in individualistic cultures, where transcendental collective values are more salient, consumers are not inclined to distinguish between the in- and out-groups (Brewer \& Chen, 2007). As such, the need for social assimilation, while remaining prominent among those who uphold collective-oriented values, is likely to manifest to a lesser degree among individualistic than collectivistic cultures. In sum, we hypothesize the following relationships:

Hypothesis 3: Materialism positively influences social referent-seeking.

Hypothesis 4: Collective-oriented values positively moderate the relationship between materialism and social referent-seeking.

Hypothesis 4a: In individualistic cultures, transcendental collective-oriented values strengthen (positively moderate) the association between materialism and social referent-seeking.

Hypothesis 4b: In collectivistic cultures, interpersonal collective-oriented values strengthen (positively moderate) the association between materialism and social referent-seeking.

\section{Price Referent and the Scarcity Hypothesis}

Another source pertinent to conspicuous consumption is price referent, defined as the standards against which the purchase price of a good is judged (Monroe, 1973). Consumer attraction to price-related information is merited by the scarcity principle. According to the commodity theory, scarcity (or rarity) is used as a marketing instrument that influences the processing of price information to enhance the value and subjective desirability of a material possession (Hwang, Ko, \& Megehee, 2014; Lynn, 1991; Suri, Monroe, \& Koc, 2013). Objects that symbolize success tend to be high-priced or expensive relative to the average cost of similar items in the product category (Fournier \& Richins, 1991). In some ways, higher prices make consumers feel superior to others, as they depict the purchaser as one of the few who can afford to buy the product (Han, Nunes, \& Drèze, 2010).

There are two types of product scarcity (Verhallen $\&$ Robben, 1994): low supply (e.g., "limited edition" products) and high demand (e.g., "nearly sold out"). Extant research finds that materialists who are preoccupied with the status-signaling aspect of consumption respond more favorably towards low supply than high demand type of scarcity (Gierl \& Huettl, 2010; Hwang et al., 2014). This is because possessing low-supply scarcity products evokes positive feelings from being envied and respected by relevant others (Belk \& Pollay, 1985; Gierl \& Huettl, 2010). Scarce products also invoke pricequality (Sweeney, Soutar, \& Johnson, 1999) and price-prestige (Tatzel, 2002) appeal. Recognizing 
such pattern, firms tend to highlight and even manipulate the exclusivity of their products to tap into consumers' desire for rarity (Amaldoss \& Jain, 2005).

Materialists use possessions to improve their selfimage and are attracted to price symbolism to convey wealth, quality, and prestige. As such, they tend to become big spenders on luxury and prestigious brands (Hudders \& Pandelaere, 2011). Thus, it can be expected that self-oriented materialists, whose pursuit is to signal status differentiation from others, are likely to pay more attention to price information to convey their ability to afford and possess a rare object. Hence, materialism is likely to have a significant and positive influence on price referent-seeking behavior.

However, the scarcity appeal may be less alluring for those who subscribe to collective-oriented values, since ostentatious consumption based on high price carries with it the social stigma of wastefulness and extravagance. Indeed, those who partake in price-signaling conspicuous consumption are likely to be portrayed as disingenuous and selfserving individuals, which accordingly shape a negative stereotype of materialists (Van Boven et al., 2010).

We argue that the principle that opposes wastefulness and extravagance universally applies to both individualists and collectivists who uphold a collective-oriented belief. Individualists, who subscribe to transcendental collective ideals, view the exorbitant consumption of rare goods with a high price as uncharacteristic to religious and spiritual ideals that promote humility and moderation. Members of collectivistic societies may be lenient towards a conspicuous display of status. However, the expectation to display humility remains high in societies where the need to maintain a harmonious relationship remains a priority (Markus \& Kitayama, 1991). Therefore, individuals are expected not to gloat over aspirational purchases to manage others' impression of oneself and the familial unit that they represent. Consequently, collectivistic cultures are mindful in projecting a self-identity that does not offend others. In sum, we expect that collective-oriented values will negatively moderate materialistic appeal towards price referent-seeking across individualistic and collectivistic cultures.

Hypothesis 5: Materialism positively influences price referent-seeking.
Hypothesis 6: Collective-oriented values negatively moderate the relationship between materialism and price referent-seeking.

Hypothesis 6a: In individualistic cultures, transcendental collective-oriented values weaken (negatively moderate) the association between materialism and price referent-seeking.

Hypothesis 6b: In collectivistic cultures, interpersonal collective-oriented values weaken (negatively moderate) the association between materialism and price referent-seeking.

\section{Brand Referent and the Insecurity Hypothesis}

A brand referent assigns symbolic meanings to product labels and attributes, which represent an important platform for materialistic consumers to express their individual and social identities. Previous research finds that the materialists' predisposition towards high-status, prestigious, and global brands (Cleveland et al., 2009; Tatzel, 2002) is due to their underlying psychological insecurity (Dittmar et al., 2014; Rindfleisch et al., 2009). Studies based on Western consumers regularly find that highly materialistic people tend to have lower selfesteem (Chaplin \& John, 2007), greater existential insecurity (Rindfleisch et al., 2009), and less confidence in conducting social relationships (Chang \& Arkin, 2002) than non-materialists. Such insecurity can be traced back to a childhood development that is guided by a parenting style that overly emphasizes material rewards over social nurturance (Kasser, 2002; Richins \& Chaplin, 2015). These findings explain why materialistic consumers seek to develop brand connections to make up for the lack of meaningful social connection and to assuage their sense of insecurity (Burroughs \& Rindfleisch, 2002; Fournier, 1998).

Kim and Kramer (2015) find that materialists are likely to perceive anthropomorphized brands as "servants," defined as an outsourced provider of benefit, rather than "partners," or the co-producers of benefits (Aggarwal \& McGill, 2012). Materialistic consumers, therefore, prefer brands that promise to look after their needs (e.g., Volvo's positioning as a safety provider and protector) over brands that work with the consumer to meet their needs (e.g., Kellogg's positioning around weight-loss aid). This is because insecure materialists seek relationships that allow them to express their dominance and need of social power (Kim \& Kramer, 2015). To 
build a strong brand connection, however, materialists must engage with and invest heavily into understanding brand meanings to be able to compensate for their insecurity effectively and to communicate a more positive self-concept to others. Therefore, we can expect a positive and significant relationship between materialism and brand referent-seeking.

However, we also propose that collective-oriented values can reduce materialistic pursuit of brand referents. Particularly, the reliance on brands to assuage feelings of insecurity is less prevalent in collectivist cultures that place greater emphasis on interpersonal relationships as a source of meaning and identity. Indeed, the interpersonal connections that run deep in the fabric of collectivistic communities can bolster its members' sense of security and community (Burroughs et al., 2013), thus reducing reliance on the self-brand connection. For example, the collectivistic norms for social support improve people's ability to cope with insecurity by making them feel supported in seeking help (Frias, Shaver, \& Diaz-Loving, 2013). Collectivistic emphasis on familial bonds also reduces insecurity as close relatives often make themselves available and take personal responsibility in looking after the welfare of their family members (Triandis, Bontempo, Villareal, \& Asai, 1988).

The appeal of brand-centered consumption to assuage insecurity is also less effective among individualistic cultures, where transcendental collective values are salient. Transcendental beliefs in religiosity and maturity promulgate spiritual connections and self-actualization, which reduce existential insecurity (Schwartz, 1992; Ahuvia \& Wong, 2002). Thus, we hypothesize that materialistic pursuit on brand referent will be similarly moderated by collective-oriented values across individualistic and collectivistic societies.

Hypothesis 7: Materialism positively influences brand referent-seeking.

Hypothesis 8: Collective-oriented values negatively moderate the relationship between materialism and brand referent-seeking.

Hypothesis 8a: In individualistic cultures, transcendental collective-oriented values negatively moderate the relationship between materialism and brand referent-seeking.

Hypothesis 8b: In collectivistic cultures, interpersonal collective-oriented values negatively moderate the relationship between materialism and brand referent-seeking.

\section{METHODOLOGY}

\section{Sample}

The present research employs a sample of consumers from the United States, China, India, and Thailand to draw a generalizable comparison of collective-oriented consumers across individualistic and collectivistic cultural clusters. Following Peterson, Søndergaard, and Kara (2017), the cluster model of country analysis assumes that cultural boundaries extend beyond single countries due to similarities in economic, institutional, and political across spatially proximal countries. We draw from Ronen and Shenkar (2013) to categorize countries into distinct clusters bearing various degrees of collective orientations. As part of the Anglo cluster, the United States is typically characterized as a highly individualistic society (Hofstede, 2001) that deeply encourages autonomy at the expense of social harmony (Schwartz, 2006). This cultural profile sets the foundation for the "American dream" that models success and happiness on the basis of monetary wealth (Kasser \& Ryan, 1993). However, US consumers also value transcendental collective ideals such as egalitarianism, religious faith, and charity (Pew Research, 2014; Schwartz, 2006; World Giving Index, 2014).

The Asian cluster is made up of a geographically and culturally diverse set of countries. We selected China, India, and Thailand as these countries represent distinct cultural clusters in Asia. China is part of the Confucian-influenced cluster (alongside Singapore, Japan, and South Korea) that centers around social hierarchy, observance of standardized rituals, and collective harmony (Chung, Eichenseher, \& Taniguchi, 2007; Ronen \& Shenkar, 2013; Schwartz, 1990). Thailand shares these Confucian traditions, but their collective ideals are also shaped largely by Buddhism, which advocates compassion and loving kindness (Pace, 2013). As such, Thailand is distinctively categorized into the Far Eastern cultural cluster (alongside Indonesia and Malaysia). India is categorized outside of the Far Eastern cluster due to its "relative dissimilarities" (Ronen \& Shenkar, 2013: 881) with the rest of the countries specified within this assemblage. India displays similar collectivistic traditions to China and Thailand, as evidenced by its hierarchical class- 
based system, commitment to tradition, conformity, and strong family ties (Batra, Ramaswamy, Alden, Steenkamp, \& Ramachander, 2000; Rose, Dalakas, \& Kropp, 2003; Schwartz, 1990). However, India is also relatively more individualistic than China and Thailand, as its religious foundation in Hinduism believes that individuals are responsible for leading the lives that positively impact on their rebirth (Hofstede, 2001). A common denominator across the Chinese, Indian, and Thai views towards collective-oriented values is the accentuation towards interpersonal relationship maintenance, which is embedded across people's daily rituals. Even the more abstract beliefs and social norms offer explicit guides for succeeding in interpersonal interactions. For example, the Eastern belief in Karma places a heavy emphasis on reciprocity in social relationships, as good actions in the present will lead to a similarly favorable outcome in the future (Kopalle, Lehmann, \& Farley, 2010).

\section{Data Collection}

We recruited 1203 respondents through convenience sampling in the United States $(n=393)$, China $(n=400)$, India $(n=210)$, and Thailand $(n=200)$. Our sample encompasses working professionals as they lived in a modern and interconnected life and had the means to participate in a materialistic culture. We employed two techniques to gather our cross-cultural data. We utilized Amazon's Mechanical Turk (MTurk) in the United States. MTurk is an online crowdsourcing platform that provides access to samples that are highly representative of the US population and therefore makes up an appropriate sample for survey research (Buhrmester, Kwang, \& Gosling, 2011). Each MTurk worker received $\$ 0.50$ for his or her participation. To control the sample to working professionals, participants were asked to identify their vocation within the questionnaire. The researchers subsequently eliminated those who were not in professional employment during the data analysis (a total of seven individuals).

We also employed graduate research assistants from a UK-based university to distribute questionnaires to working professionals in China, India, and Thailand. The research assistants recruited individuals through visits to the cafeteria in publicly accessible corporate buildings in Beijing and Guangdong in China, Mumbai in India, and Bangkok in Thailand. Respondents were approached in-person and asked to participate voluntarily in a short academic survey. This approach diminishes the non-response bias that could potentially under-represent certain survey respondents (Blair \& Zinkhan, 2006). Research assistants controlled the sample selection through verbal interactions with the participants to determine their nationalities, employment status, and the English proficiency (of our Indian participants) through quick interactions. Our sample demographic shows that overall females comprised $52.4 \%$ of the whole sample, while participants aged 20 to 29 years $(37 \%)$ comprised the largest age segment of our respondents. The full demographic information of our sample is available in Web Appendix 1.

\section{Measures}

We measured materialism using a nine-item version of Richins and Dawson's (1992) Material Value Scale (MVS), validated by Richins (2004). Although other competing measures of materialism are available, such as Belk's (1985) three-dimensional measure of materialism (including envy, nongenerosity, and possessiveness), the MVS remains the most validated scale of materialism across various contexts and countries (e.g., Chang \& Arkin 2002; Cleveland et al. 2009), which fits the cross-cultural nature of the present study.

The collective-oriented value system was assessed based on the ten-item Short Schwartz Value Survey (SVSS), validated by Lindeman and Verkasalo (2005). Four dimensions of values appear in Schwartz's quasi-circular structure: openness to change, self-enhancement, conservation, and selftranscendence. Schwartz's (1992) structure of human values outlines the conflicts between conservation versus openness to change and self-transcendence versus self-enhancement. Following Schwartz et al. (2001), we measure transcendental collective-oriented values (TCOV) using two items: universalism and benevolence. Meanwhile, the dimension of interpersonal collective-oriented values (ICOV) is measured by three items: tradition, conformity, and security values.

We developed a measurement scale for referentseeking behavior to address the lack of compatible measures in the literature that capture consumers' search for relevant sources that inject meanings into their conspicuous consumption. Referentseeking behavior was measured as a reflective construct with a three-factor structure that encompasses price (PR), social (SR), and brand referents (BR). Price, brand, and social referent-seeking consisted of three, four, and three items, respectively. 
Before completing the questionnaire, participants were tasked to reflect on their last purchases of business attire. Such purchasing context is relevant to both materialists and non-materialists alike, but business attire is particularly meaningful and important to materialists since it offers both selfand other-signaling capacity to demonstrate the cultural membership, status, style, and social class (Cleveland et al., 2009) of the purchaser.

We administered back-translation of our original English survey into Chinese (Mandarin) and Thai to ensure translation equivalence across cultures (Hult et al., 2008; Mullen, 1995). We did not translate the survey into Hindi due to the sizeable proportion of fluent English speakers within our Indian professional network. Following Brislin (1970), we employed two native speakers of Chinese and Thai, respectively, to conduct the back-translations. The translation team includes one of the co-authors of the present study, who is a native Chinese speaker, and professional translators based in China and Thailand. During the process, minor semantic differences were discussed and resolved by modifying the translation until accuracy in meanings was achieved.

\section{Measurement Validation}

We conducted exploratory factor analysis (EFA) on the measures for materialism, values, and referents to examine their psychometric properties. In examining MVS, we find that the reverse-worded item in MVS ("I try to keep my life simple, as far as possessions are concerned") consistently displayed non-significant, low factor loadings (loadings $<0.05$, $p>0.05)$ across the Chinese, Indian, and Thai samples. This is consistent with Wong et al.'s (2003) findings, which subsequently concluded the item as inappropriate for cross-cultural research. Upon the removal of this item, MVS displayed strong psychometric properties across the US, China, India, and Thailand (Mean $\alpha=0.79$; range $\alpha=0.73$ to 0.86 ). Thus, from this point onwards, materialism was measured using the eight-item MVS scale. Meanwhile, the EFA results showed that the measures for TCOV and ICOV demonstrated satisfactory psychometric properties (loadings $<0.05, p>0.05$; Mean $\alpha=0.85$; range $\alpha=0.72$ to 0.90 ) across all groups.

In testing the new measurement scale for referents, we first conducted a pretest of the ten-item measure of referent-seeking behavior on a convenience sample of 425 participants recruited from our graduate assistants' professional network in Athens, Greece. Greeks place a high value on both personal autonomy and interdependence (Rose et al., 2003). As such, it offers a suitable context for a pretest since the Greeks share similar cultural profiles with the US in terms of self-orientation and with China, India, and Thailand with regard to others-orientation. This sample of professionals offers an equivalent, yet a distinct group of respondents to the sample in the main study, thus enhancing the parsimony of the new measure across cultures.

The results of the confirmatory factor analysis (CFA) showed a good internal consistency of the three-factor model (Table 1). We subsequently removed one item from the analysis due to its low loading (0.48). The resulting model improved significantly (loadings $>0.61 ; \alpha>0.75$; AVE $>0.50$ ). As a test of discriminant validity, we followed Anderson and Gerbing's (1988) Chi-square difference test by comparing the baseline model $\left(\chi^{2} / d f=10.44\right.$, $p<0.01)$ against a three-factor correlated model $\left(\chi^{2} / d f=1.59 ; p<0.05\right)$. The result demonstrates that the latter is a statistically better model than the baseline model $(p<0.05)$. Replication from the US, China, India, and Thailand further demonstrates the new measure's strong psychometric properties (Mean $\alpha=0.75$; Range $\alpha=0.70$ to 0.89 ).

We subsequently tested the fit of a measurement model that includes the scales of materialism, collective-oriented values (TCOV and ICOV), and referents (PR, SR, and BR). Confirmatory factor analyses (CFA) of the measurement model were conducted on the US, Chinese, Indian, and Thai datasets using the Maximum Likelihood (ML) estimation procedure with Mplus (Muthén \& Muthén, 2013). This model yielded acceptable model fit with the sample data from the US $\left(\chi^{2} / d f=2.19 ;\right.$ RMSEA $=0.05$; $\mathrm{CFI}=0.93 ; \mathrm{TLI}=0.92 ;$ SRMR $=0.06)$, China $\left(\chi^{2} /\right.$ $d f=2.25 ; \quad \mathrm{RMSEA}=0.05 ; \mathrm{CFI}=0.91 ; \mathrm{TLI}=0.90$; SRMR $=0.06)$, India $\left(\chi^{2} / d f=0.82 ;\right.$ RMSEA $=0.05$; $\mathrm{CFI}=0.92 ; \mathrm{TLI}=0.91 ; \mathrm{SRMR}=0.06)$, and Thailand $\left(\chi^{2} / d f=1.60 ; \quad\right.$ RMSEA $=0.05 ; \quad$ CFI $=0.95 ; \quad$ TLI $=$ 0.94; SRMR $=0.04$ ). All factor loadings were statistically significant, with the lowest loading being 0.55 . Additionally, $t$ values for all variables were statistically significant (>1.96), composite reliability is greater than the recommended 0.70, and AVE scores were higher than or equal to 0.50 . Thus, the measurement fulfills the criteria for convergent validity. A test of discriminant validity (Anderson \& Gerbing, 1988) was subsequently implemented by constraining factor covariance to 1 . This produced significantly worse Chi-square statistics $\left(\Delta \chi^{2}=9425, \Delta d f=15\right.$, $p<0.01)$, which provide support for discriminant and convergent validity of the measurement model. 
Table 1 Measurement model of consumer referents (pilot study $n=425$ )

\begin{tabular}{ll}
\hline Measurement & Loadings \\
\hline Price Referent-Seeking & 0.84 \\
Cronbach's $\alpha$ & 0.88 \\
PRS1 Before making a purchase decision, I paid attention to sales information & 0.88 \\
PRS2 Before making a purchase decision, I look around for the best price & 0.82 \\
PRS3 Before making a purchase decision, I considered price-related information & 0.75 \\
Social Referent-Seeking & 0.63 \\
Cronbach's $\alpha$ & 0.71 \\
SRS1 Before making a purchase decision, I asked my colleagues' opinions & 0.75 \\
SRS2 Before making a purchase decision, I asked my family member's opinions \\
SRS3 My concern about people's opinions of me affected my purchase \\
Brand Referent-Seeking \\
Cronbach's $\alpha$ \\
BRS4 Before making a purchase decision, I considered the associated reliability of the brand \\
BRS5 Before making a purchase decision, I considered the reputation of the brand \\
BRS6 Before making a purchase decision, I considered whether it was a domestic or a global brand
\end{tabular}

Figures in italics denote the values of Cronbach's alpha.

\section{Measurement Invariance}

We subsequently performed a series of tests of multigroup invariance to examine the equivalence of the proposed measurement model across the four country samples. Invariance tests involve a set of analyses in which a well-fitting multigroup baseline model is developed and compared to subsequent tests with increasingly restricted parameters (Byrne, 2008). We used the US data as the baseline because MVS was developed in the United States. Following Cheung and Rensvold (2002), we determined measurement equivalence based on the changes in CFI, Gamma-hat (Steiger, 1989), and Non-Centrality Index (McDonald, 1989) in relation to the configural (baseline) model, since these fit indices are the least sensitive to sample size and model complexity. Invariance is supported when changes in fit indices fall within the recommended cut-off points $(\Delta \mathrm{CFI}<-0.01, \Delta \mathrm{GH}<-0.001$, and $\Delta \mathrm{NCI}<-0.2)$.

Table 2 shows the fit indices for the configural, full metric, and partial metric invariance models. We first established configural invariance (where factor loadings were freely estimated) of the measurement model to determine whether the measurement items exhibit the same factor structure across groups. This test yielded a satisfactory fit, which permits subsequent analysis of metric invariance (where factor loadings were constrained to equality). However, the full metric invariance yielded a significantly worse model $(\Delta \mathrm{CFI}=0.03$, $\Delta \mathrm{GH}=0.003, \quad \Delta \mathrm{NCI}=0.03) . \quad$ Nevertheless, we achieved a partially invariant model by removing the equality constraint on two items. First, "benevolence" was higher in parameter estimates in the US than in China, India, and Thailand, suggesting that the value of kindness is more prevalent across the US than the collectivistic societies in our sample. This is unsurprising since the United States ranks first place in the world for charitable giving behaviors that include helping a stranger, volunteering time, and donating money (World Giving Index, 2014). Second, the item SRS3, "my concern about people's opinions of me affected my purchase" was lower among Americans, which suggests that social referencing is more prevalent across China, India, and Thailand than in the US. The partial metric invariance model did not differ significantly from the baseline model $(\Delta \mathrm{CFI}=0.01, \Delta \mathrm{GH}=0.001, \Delta \mathrm{NCI}=0.02)$, which indicates that the measures can be meaningfully compared across countries (Steenkamp \& Baumgartner, 1998). Table 3 shows the factor loading estimates of partial metric invariance. Overall, the fulfillment of convergent, discriminant validity and multigroup invariance of the measurement scales permit further hypothesis testing.

\section{Hypothesis Testing}

We employed two different sets of data analysis techniques to test our hypotheses. The first and second hypotheses postulate correlational relationships between materialism and collective-oriented values. We tested these relationships using both correlation analysis and multidimensional scaling (MDS). MDS provides a graphical representation of how respondents perceive each value relative to one another in a two-dimensional conceptual 
Table 2 Measurement model comparison

\begin{tabular}{llllll}
\hline & $X^{2} / d f$ & RMSEA & TLI & CFI & GH \\
\hline Configural (baseline) & 1.92 & 0.05 & 0.93 & 0.94 & 0.998 \\
Full metric & 2.26 & 0.06 & 0.90 & 0.91 & 0.95 \\
Partial metric & 1.95 & 0.05 & 0.92 & 0.93 & 0.995 \\
\hline
\end{tabular}

Table 3 Measurement model invariance

\begin{tabular}{|c|c|c|c|c|}
\hline \multirow[t]{2}{*}{ Variables } & \multicolumn{4}{|c|}{ Factor loading estimates } \\
\hline & US & China & India & Thailand \\
\hline \multirow[t]{2}{*}{ MAT1 } & 1.00 & 1.00 & 1.00 & 1.00 \\
\hline & - & - & - & - \\
\hline \multirow[t]{2}{*}{ MAT2 } & 0.78 & 0.78 & 0.78 & 0.78 \\
\hline & $(19.73)$ & $(19.73)$ & $(19.73)$ & $(19.73)$ \\
\hline \multirow[t]{2}{*}{ MAT3 } & 0.96 & 0.96 & 0.96 & 0.96 \\
\hline & $(21.86)$ & $(21.86)$ & $(21.86)$ & $(21.86)$ \\
\hline \multirow[t]{2}{*}{ MAT5 } & 0.88 & 0.88 & 0.88 & 0.88 \\
\hline & $(20.53)$ & $(20.53)$ & $(20.53)$ & $(20.53)$ \\
\hline \multirow[t]{2}{*}{ MAT6 } & 0.99 & 0.99 & 0.99 & 0.99 \\
\hline & $(22.48)$ & $(22.48)$ & $(22.48)$ & $(22.48)$ \\
\hline \multirow[t]{2}{*}{ MAT7 } & 0.95 & 0.95 & 0.95 & 0.95 \\
\hline & $(20.87)$ & $(20.87)$ & $(20.87)$ & $(20.87)$ \\
\hline \multirow[t]{2}{*}{ MAT8 } & 1.01 & 1.01 & 1.01 & 1.01 \\
\hline & $(21.22)$ & $(21.22)$ & $(21.22)$ & $(21.22)$ \\
\hline \multirow[t]{2}{*}{ МАT9 } & 0.93 & 0.93 & 0.93 & 0.93 \\
\hline & $(19.91)$ & (19.91) & (19.91) & (19.91) \\
\hline \multirow[t]{2}{*}{ Universalism } & 1.00 & 1.00 & 1.00 & 1.00 \\
\hline & - & - & - & - \\
\hline \multirow[t]{2}{*}{ Benevolence } & 1.15 & 0.98 & 0.98 & 0.98 \\
\hline & $(28.34)$ & $(25.33)$ & $(25.33)$ & $(25.33)$ \\
\hline \multirow[t]{2}{*}{ Tradition } & 1.15 & 1.15 & 1.15 & 1.15 \\
\hline & $(28.33)$ & (28.33) & $(28.33)$ & $(28.33)$ \\
\hline \multirow{2}{*}{ Conformity } & 1.16 & 1.16 & 1.16 & 1.16 \\
\hline & $(28.38)$ & $(28.38)$ & $(28.38)$ & $(28.38)$ \\
\hline \multirow[t]{2}{*}{ Security } & 0.99 & 0.99 & 0.99 & 0.99 \\
\hline & $(25.84)$ & $(25.84)$ & $(25.84)$ & $(25.84)$ \\
\hline \multirow[t]{2}{*}{ PRS1 } & 1.00 & 1.00 & 1.00 & 1.00 \\
\hline & - & - & - & - \\
\hline \multirow[t]{2}{*}{ PRS2 } & 1.17 & 1.17 & 1.17 & 1.17 \\
\hline & $(18.74)$ & (18.74) & (18.74) & (18.74) \\
\hline \multirow[t]{2}{*}{ PRS3 } & 1.20 & 1.20 & 1.20 & 1.20 \\
\hline & $(19.40)$ & (19.40) & $(19.40)$ & $(19.40)$ \\
\hline \multirow[t]{2}{*}{ SRS1 } & 1.00 & 1.00 & 1.00 & 1.00 \\
\hline & - & - & - & - \\
\hline \multirow[t]{2}{*}{ SRS2 } & 1.02 & 1.02 & 1.02 & 1.02 \\
\hline & (30.59) & (30.59) & $(30.59)$ & $(30.59)$ \\
\hline \multirow[t]{2}{*}{ SRS3 } & 0.77 & 1.88 & 1.88 & 1.88 \\
\hline & $(16.23)$ & $(7.67)$ & $(7.67)$ & (7.67) \\
\hline \multirow[t]{2}{*}{ BRS1 } & 1.00 & 1.00 & 1.00 & 1.00 \\
\hline & - & - & - & - \\
\hline \multirow[t]{2}{*}{ BRS2 } & 1.31 & 1.31 & 1.31 & 1.31 \\
\hline & $(21.90)$ & (21.90) & (21.90) & $(21.90)$ \\
\hline \multirow[t]{2}{*}{ BRS3 } & 0.97 & 0.97 & 0.97 & 0.97 \\
\hline & (16.08) & (16.08) & (16.08) & (16.08) \\
\hline
\end{tabular}

Note: Values in parentheses denote $t$ values. 
space, which offers an integrative means of examining the distances between material and collective-oriented values. Meanwhile, H3 to H8 were tested using hierarchical regression to examine the direct relationships between materialism and social, price, and brand referent-seeking, and the role of transcendent and interpersonal collectiveoriented values in moderating these relationships. Further, we conducted simple slope analyses to understand the nature of these value interactions better. This process involves creating high and low conditional values determined by one standard deviation above and below the mean for materialism, transcendental, and interpersonal collectiveoriented values.

\section{Materialism and Collective-oriented Values}

$\mathrm{H} 1$ and $\mathrm{H} 2$ were tested using both correlation analysis and MDS to evaluate how respondents from four countries perceived each value relative to one another in a two-dimensional conceptual space. The correlations between materialism and collective-oriented values (see Web Appendix 2-5) were used to generate the distances used in MDS analysis (see Web Appendix 6-9). Subsequently, MDS analysis was operationalized on the standardized values of these correlations using the ALSCAL algorithm to compute proximities (Kruskal, 1964). The MDS solution generated Stress scores of 0.05, 0.04, and 0.07 in China, India, and Thailand, respectively, and 0.18 in the US. The $\mathrm{R}^{2}$ value was 0.99 in China, 0.93 in India, 0.92 in Thailand, and 0.86 in the US, suggesting an adequate representation of the data (Kruskal, 1964).

The results of the bivariate correlation among the US group showed negative correlations between materialism and collective-oriented values, including universalism $(r=-0.12, p<0.05)$, benevolence $(r=-0.09, \quad p<0.05), \quad$ conformity $\quad(r=-0.11$, $p<0.05)$, security $(r=-0.11, p<0.05)$ and tradition $(r=-0.09, p<0.05)$. As predicted by Burroughs and Rindfleisch (2002), materialism in the US was positively correlated with self-oriented values, including power $(r=0.52, p<0.01)$, achievement $(r=0.32$, $p<0.01)$, hedonism $(r=0.48, p<0.01)$, stimulation $(r=0.33, p<0.01)$ and self-direction $(r=0.17$, $p<0.05$; see Web Appendix 2). However, bivariate correlation analysis on the Chinese, Indian, and Thai consumers showed that materialism was significantly and positively correlated to both self- and collectiveoriented values (see Web Appendix 3, 4, and 5). Specifically, positive correlations were observed between materialism and self-oriented values including power $\quad\left(r_{\text {China }}=0.51, \quad r_{\text {India }}=0.22\right.$, $\left.r_{\text {Thai }}=0.19 p<0.01\right)$, achievement $\left(r_{\text {China }}=0.32\right.$, $\left.r_{\text {India }}=0.32, \quad r_{\text {Thai }}=0.29, \quad p<0.01\right), \quad$ hedonism $\left(r_{\text {China }}=0.48, r_{\text {India }}=0.24, r_{\text {Thai }}=0.29, p<0.01\right)$, stimulation $\left(r_{\text {China }}=0.33, r_{\text {India }}=0.23, r_{\text {Thai }}=0.18\right.$ $p<0.01)$, and self-direction $\quad\left(r_{\text {China }}=0.16, \quad r_{\text {In- }}\right.$ dia $\left.=0.16, r_{\text {Thai }}=0.12, p<0.01\right)$. Materialism was also positively correlated with collective-oriented values that were centered on interpersonal relationship maintenance, including universalism $\left(r_{\text {India }}=\right.$ $\left.0.09, p<0.01 ; r_{\text {Thai }}=0.15, p<0.01\right)$, benevolence $\left(r_{\text {China }}=0.10, r_{\text {India }}=0.12, r_{\text {Thai }}=0.22, p<0.01\right)$, tradition $\left(r_{\text {China }}=0.32, r_{\text {India }}=0.24, r_{\text {Thai }}=0.27\right.$, $p<0.01)$, conformity $\left(r_{\text {China }}=0.12, \quad r_{\text {India }}=0.19\right.$, $\left.r_{\text {Thai }}=0.25, p<0.01\right)$, and security $\left(r_{\text {China }}=0.11\right.$, $\left.p<0.05 ; \quad r_{\text {India }}=0.15, \quad r_{\text {Thai }}=0.20, p<0.01\right)$. An exception to the rule was China, where there was a non-significant correlation between materialism and universalism $\left(r_{\text {China }}=0.06 p>0.05\right)$.

A subsequent analysis of the MDS plots (Figure 2) illustrates the value arrangements among consumers from the US, China, India, and Thailand, respectively. In line with Schwartz's $(1990,1992)$ model, value arrangements across all countries demonstrate conflicting placements of self-oriented values (power, achievement, stimulation, hedonism, selfdirection) and collective-oriented values (universalism, benevolence, conformity, tradition, security). However, distinct patterns were emerging in relation to the perceived distance between materialism and collective-oriented values across countries. In the US sample, the Euclidean distances between materialism (Web Appendix 6), indicate that materialism was conceptually proximal with the cluster of self-oriented values and was adjacent to collective-oriented values. Thus, MDS test in the US (Figure 2, panel 1) situates materialism within the cluster of self-oriented values, most notably achievement, stimulation, and hedonism. Overall, the results from our US data support Burroughs and Rindfleisch's (2002) findings whereby materialism in individualistic culture is negatively related to collective-oriented values. Thus H1 is supported. Conversely, panels 2, 3, and 4 in Figure 2 show a narrower set of Euclidean distances between materialism and collective-oriented values in the Chinese, Indian, and Thai groups, suggesting that these participants perceive conceptual similarities between materialism and collective-oriented values. Overall, these findings provide support for $\mathrm{H} 2$.

A notable difference across the Asian groups in our study is that the proximities between materialism and collective-oriented values were distinctively 

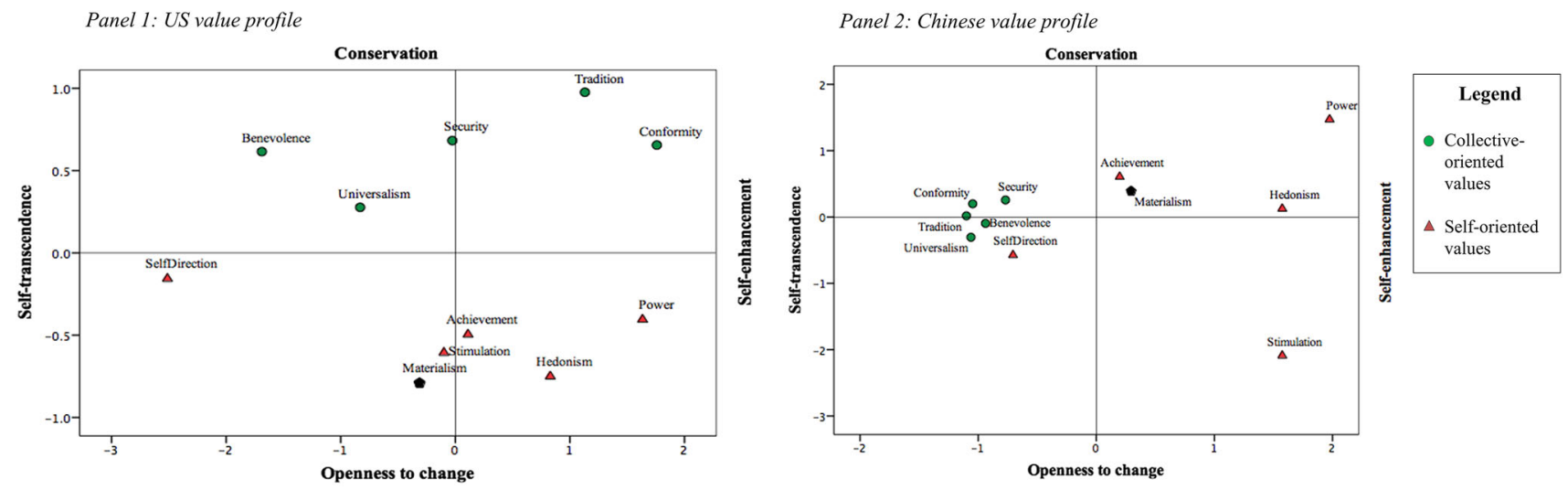

Panel 3: Indian value profile

Panel 4: Thai value profile
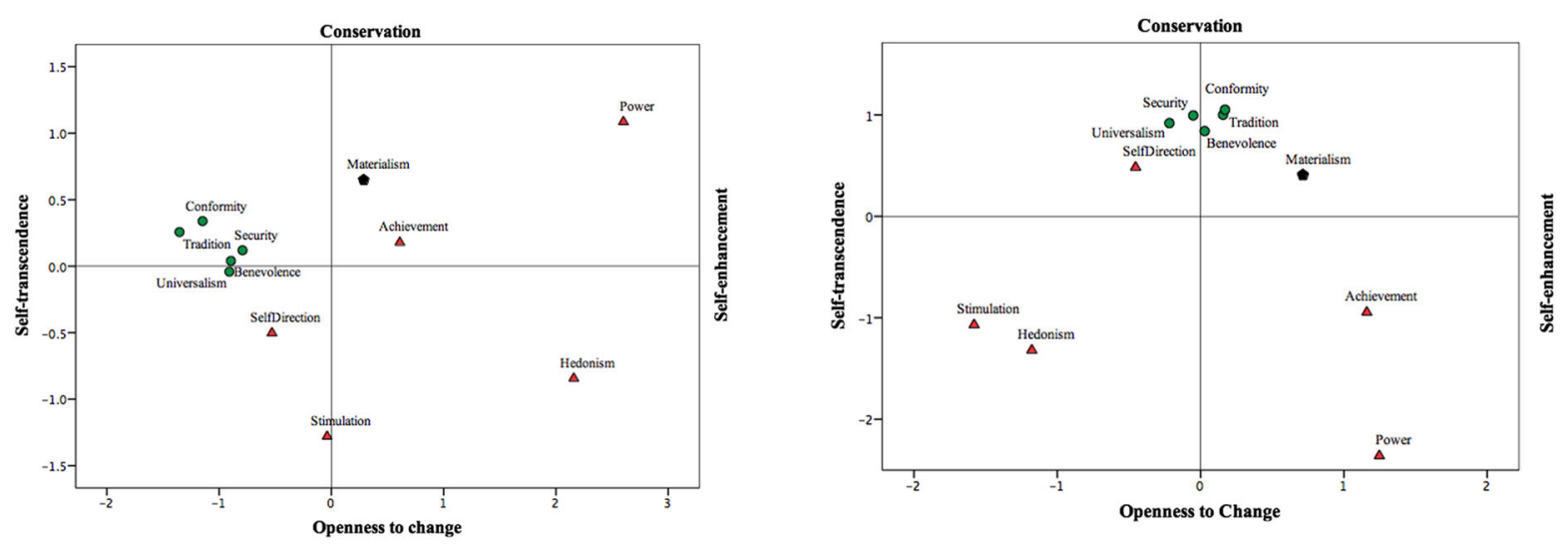

Figure 2 MDS plot of consumer value profile in the US, China, India, and Thailand.

narrower and more clustered among the Thai than the Indian and Chinese groups. Such intracultural variations are natural due to these communities' varying histories and identities. The Chinese and Indian groups perceived strong conceptual similarities between materialism with the interpersonal dimension of collective-oriented values (i.e., "tradition," "security", and "conformity"), while the Thai group perceives materialism to be proximal to both interpersonal and transcendental dimensions of collective-oriented values (i.e., "benevolence" and "universalism"). Such strong value alignment may be explained by the Buddhist foundation combined with the Confucian influence in Thai social norms, which appear to make Thai consumers relatively comfortable with accepting interpersonal and transcendental collective-oriented materialism as part of the natural order (Wong et al., 2003).

\section{Materialism and Referents}

Having examined the location of materialism within Schwartz's value structure, we established the necessary foundation for examining the hypothesis that collective-oriented values moderate materialistic pursuit of conspicuous referent-seeking (H3 to H8). Before testing these hypotheses, we tested the claims of previous research that interpersonal collective-oriented values (ICOV) are more salient in collectivistic than in individualistic cultures, and vice versa regarding transcendental collective values (TCOV; Brewer \& Chen, 2007; Schwartz, 1990; Triandis, 1995). The results of one-way ANOVA suggest that there is a statistically significant difference in the prevalence of $\operatorname{ICOV}\left(\mathrm{F}_{(3,1199)}=8.55, p=0.00\right)$ and TCOV $\left(\mathrm{F}_{(3,1199)}=12.03, p=0.00\right)$ across the US, China, India, and Thailand groups.

On average, ICOV is significantly lower among the US participants $(\mathrm{M}=4.89, \mathrm{SD}=1.80)$ in comparison to Chinese $(\mathrm{M}=5.94, \mathrm{SD}=1.67)$, Indian $(\mathrm{M}=6.04, \quad \mathrm{SD}=1.41)$, and Thai $(\mathrm{M}=5.71$, $\mathrm{SD}=1.42$ ) participants. In contrast, US consumers reported a significantly higher average of TCOV $(\mathrm{M}=6.54, \mathrm{SD}=1.41)$ than Chinese $(\mathrm{M}=5.61$, $\mathrm{SD}=1.82)$, Indian $(\mathrm{M}=5.54, \mathrm{SD}=1.42)$, and Thai $(\mathrm{M}=5.54, \mathrm{SD}=1.38)$ participants. Post hoc 
comparison using Scheffe test indicated that both the ICOV and TCOV mean scores for the US group were significantly different than those for the Chinese, Indian, and Thai groups. However, there were no significant differences between Chinese, Indian, and Thai groups in terms of ICOV and TCOV mean scores. Supporting extant research, these findings indicate that transcendental values were more predominant in an individualistic culture such as the US (individualism score of 91; Hofstede, 2001), in comparison to collectivistic cultures such as China (20) Thailand (20), and India (48), where interpersonal values were greatly esteemed.

Following Cohen and Cohen (1983), we subsequently conducted hierarchical regression to examine $\mathrm{H} 3$ to $\mathrm{H} 8$. This approach involves two sets of regression analyses: first, the main-effect relationships, where materialism represented the independent variable and social (H3), price (H5), and brand referents (H7) represented the dependent variables; second, a higher-order model that included the independent and dependent variables, as well as the interaction between materialism and collectiveoriented values (MAT $\mathrm{x}$ ICOV; MAT $\mathrm{x}$ TCOV) to examine the moderating effect of ICOV and TCOV on these direct relationships. All variables were mean-centered to reduce multicollinearity between the main effects and the interaction terms (Aiken, West, \& Reno, 1991). In these models, we included gender, age group, education, and income as covariates. A test of moderation is indicated by a significant two-way interaction between the independent and moderating variables. Tables 4,5 , and 6 show the full results of the regression analysis on the independent, dependent, and moderator variables.

As shown at the top lines on Tables 4, 5, and 6, materialism has positive and significant relationships with social (min: $b_{\text {India }}=0.13, p<0.01$; $\max$ : $\left.b_{\mathrm{US}}=0.24, p<0.01\right)$, price $\left(\min : b_{\mathrm{US}}=0.12\right.$, $p<0.05$; max: $\left.b_{\text {India }}=0.36, p<0.01\right)$, and brand referent-seeking (min: $b_{\mathrm{US}}=0.12, p<0.05$; max: $\left.b_{\text {China }}=0.32, p<0.01\right)$ across all country groups, supporting $\mathrm{H} 3, \mathrm{H} 5$, and $\mathrm{H} 7$, respectively. The results also suggest that collective-oriented values significantly moderate the materialism-referent relationship. In the US, transcendental collective values (universalism and benevolence) were found to be significant negative moderators on materialism and social, price, and brand referent-seeking, which contradicts $\mathrm{H} 4 \mathrm{a}$. In contrast, interpersonal collective values positively moderate the same relationships in China, India, and Thailand,

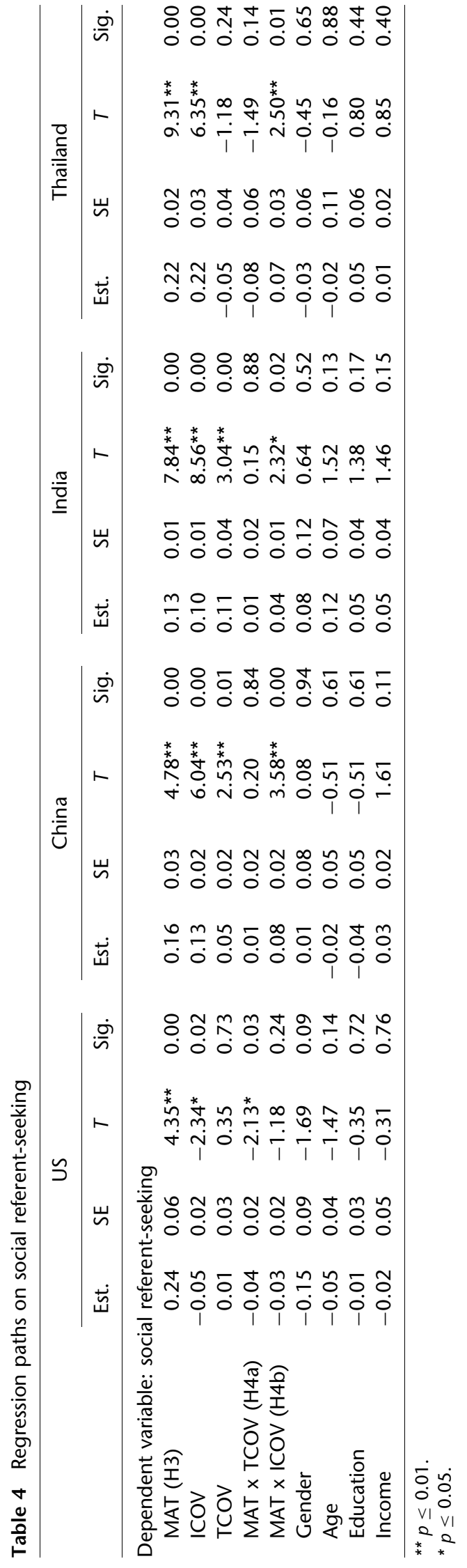



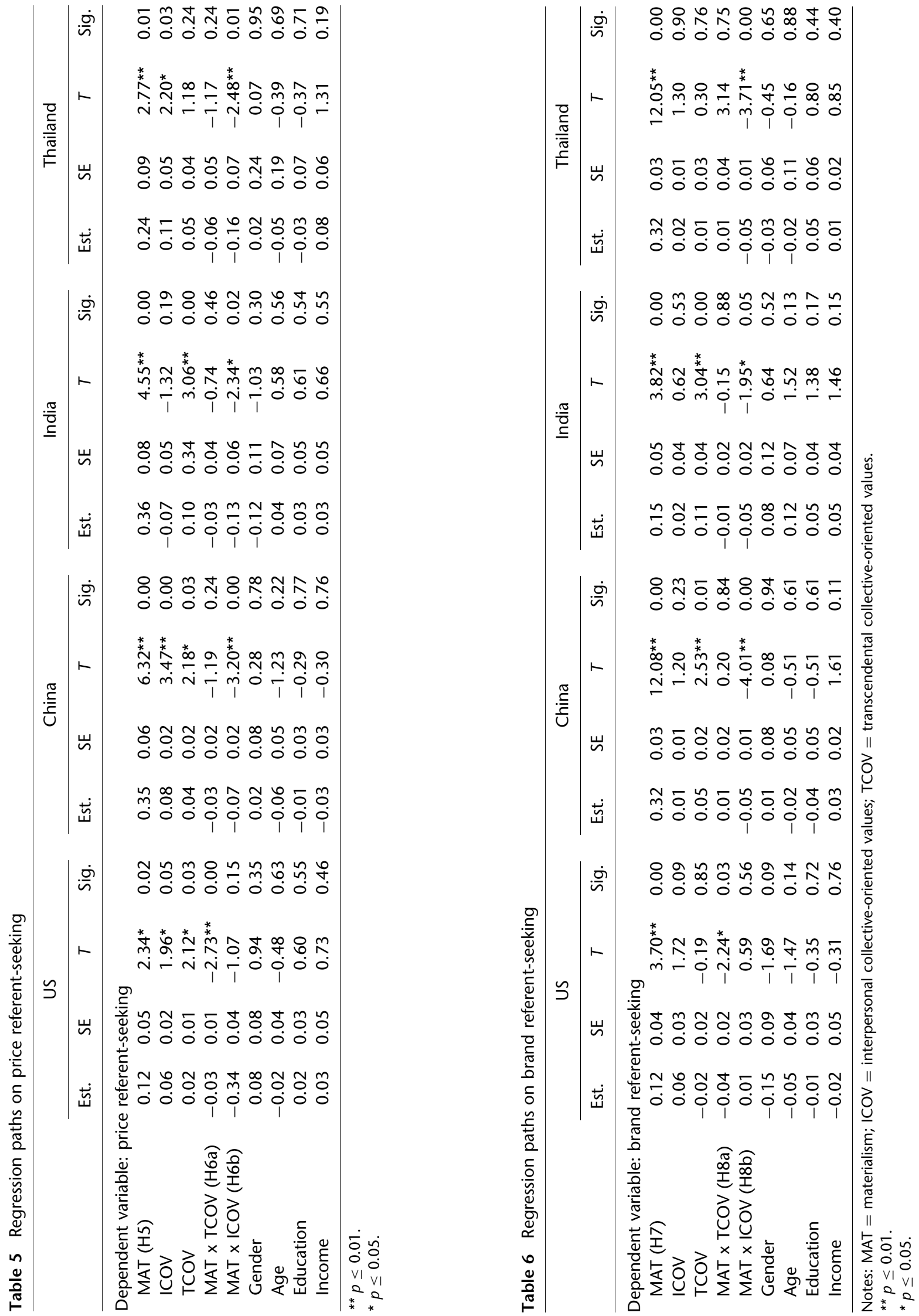
consistent with $\mathrm{H} 4 \mathrm{~b}$. The values of interaction effects are displayed within the dotted areas on Tables 4, 5, and 6 .

Furthermore, simple slope analyses reveal that collective-oriented values tend to reduce the strength of the relationships between materialism and conspicuous referent-seeking (Figures 3, 4, and 5). Contrary to $\mathrm{H} 4 \mathrm{a}$, the US results suggest that TCOV reduces the strength of materialistic appeal towards social referent. Therefore $\mathrm{H} 4 \mathrm{a}$ is not supported. This finding suggests that the collectiveoriented materialists in individualistic societies, who subscribe to transcendental values, are likely to have an overall reduced interest towards all forms of conspicuous consumption. In contrast, results in China, India, and Thailand groups show that ICOV positively moderates the relationship between materialism and social referent-seeking in our Asian sample, hence supporting H4b.

The simple slope analysis further suggests that TCOV in the US significantly reduced the effects of materialism on price and brand referent-seeking, therefore supporting $\mathrm{H} 6 \mathrm{a}$ and $\mathrm{H} 8 \mathrm{a}$, respectively. Likewise, in China, India, and Thailand, ICOV also negatively moderate the relationships between materialism and price and brand referentseeking, hence supporting H6b and H8b. Overall, the significant interaction effects between materialism and collective-oriented values on conspicuous referent-seeking provide support for a predominant part of our hypotheses. The results of our hypothesis testing are summarized in Table 7.

\section{DISCUSSION}

Extant research and practice had overwhelmingly focused on the selfish characterization of materialism. The present research demonstrates that there is a selfless side to materialism that is concerned with collective-oriented values and social commitments. In a reassessment of the self-oriented view of materialism, we theorize that the value that materialists assign to possessions and acquisitions is determined by the extent to which their individual orientation of material value conflicts with collective-oriented value. Our findings highlight key differences between self- and collective-oriented materialism in terms of their value structure and conspicuous consumption deliberation.

Self-oriented materialism takes place when the primacy that one ascribes to possessions and acquisitions is more aligned with the goals, beliefs, and values that are oriented towards fulfilling self-interests than the interests of the collective. As such, highly materialistic consumers perceive material value as antithetical to collective-oriented values (Burroughs \& Rindfleisch, 2002). Self-oriented materialists are also meaning seekers who pursue purpose and connection through material goods (Rindfleisch et al., 2009). Our research shows that self-oriented materialists across the US, China, India, and Thailand subscribe to the symbolic aspect of conspicuous consumption. Thus, they place equal emphasis on the social, price, and brand symbolism in their prepurchase deliberation.

Echoing extant research (Burroughs \& Rindfleisch, 2002; Wong et al., 2003), our result suggests that on average the US consumers reported high perceptual distance between materialism and collective-oriented values. This shows that the selforiented culture of materialism remains rife in the United States. However, the US group in our study also demonstrated a stronger emphasis on transcendental collective-oriented values than the Chinese, Indian, and Thai samples. Transcendental values center on the religious and spiritual embodiment of the collective, but also promote resistance and resilience from materialistic pursuits (Cleveland \& Chang, 2009; Pace, 2013). Such anti-materialism ideology is likely to incite a sense of value conflict among those who seek to balance materialistic and collectivistic priorities.

We hypothesized that collective-oriented materialism occurs when the value that one assigns to material goods aligns and positively correlates with collective-oriented values. We find evidence of such value alignment in the Chinese, Indian, and Thai groups, suggesting that on average Asian materialists are more likely to reconcile material and collective-oriented values through their possessions and acquisitions than their US counterparts. Nevertheless, our empirical results show that collective-oriented materialism is present across all our country groups, although it manifests varyingly across cultures. Collective-oriented materialism manifests when the salient interpretation of the collective in each culture reduces materialistic pursuits of conspicuous consumption. Indeed, aside from dispensing self-promotional capacities, conspicuous consumption also offers others-signaling properties (Shrum et al., 2013, 2014) that allow collective-oriented materialists to grant status to their in-groups, enable compliance with social expectations, demonstrate belongingness, and fulfill their perceived social responsibilities. 
Panel A: Transcendental collective-oriented values in the US reduces materialistic pursuit of social referent

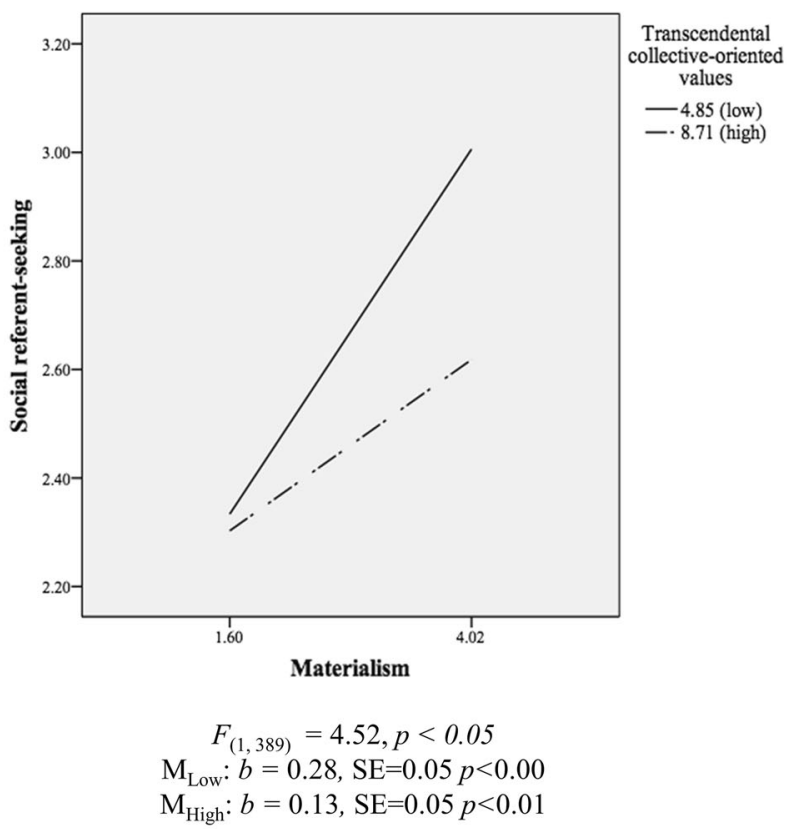

Panel B: Interpersonal collective values in India increase materialistic pursuit of social referent

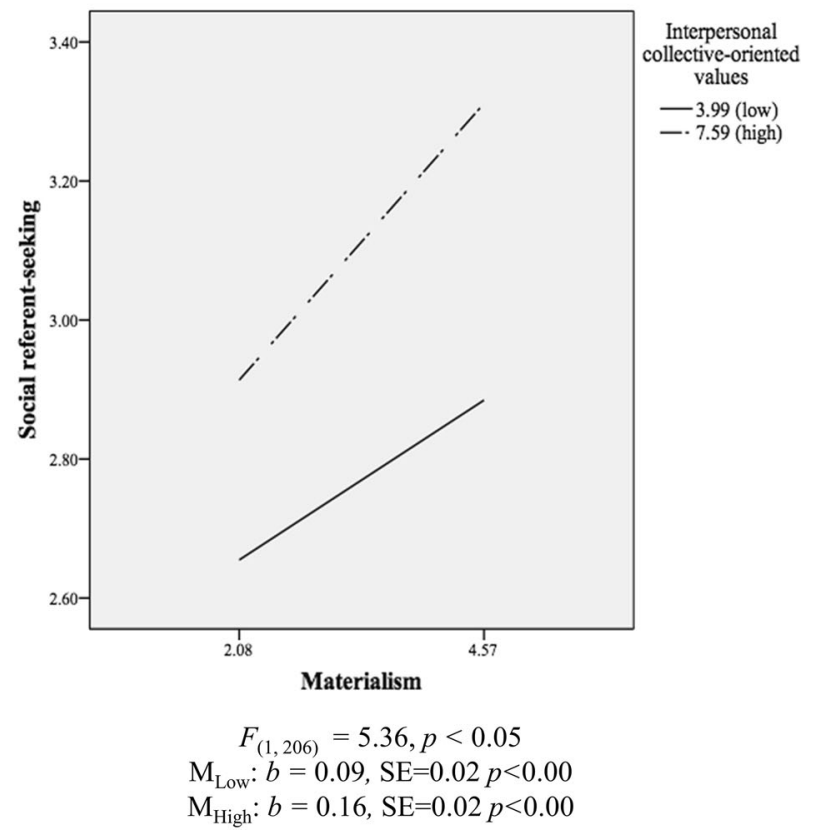

Panel B: Interpersonal collective values in China increase materialistic pursuit of social referent

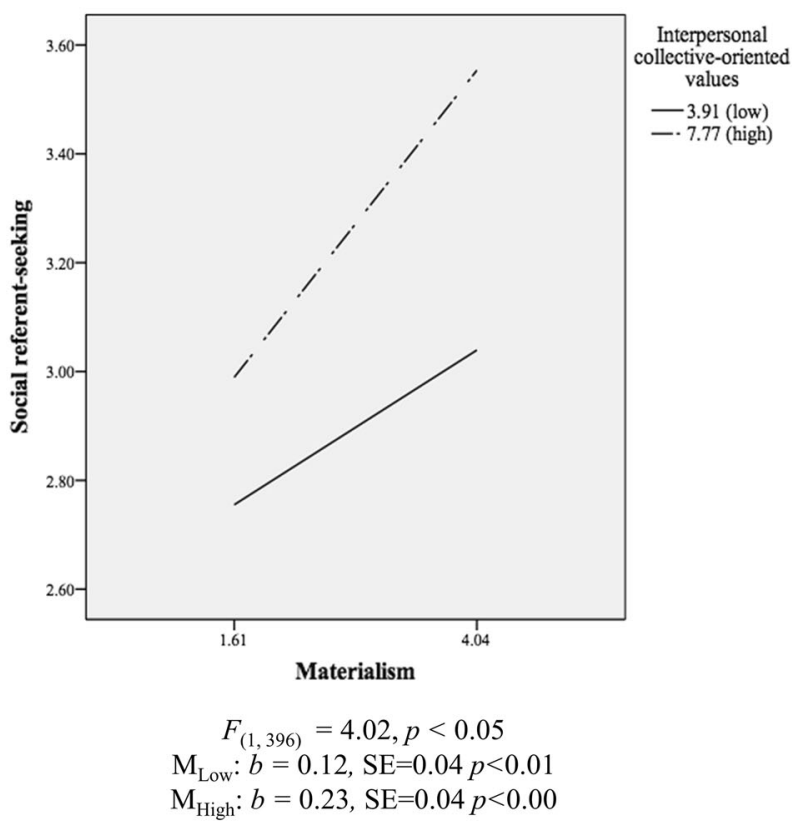

Panel D: Interpersonal collective values in Thailand increase materialistic pursuit of social referent.

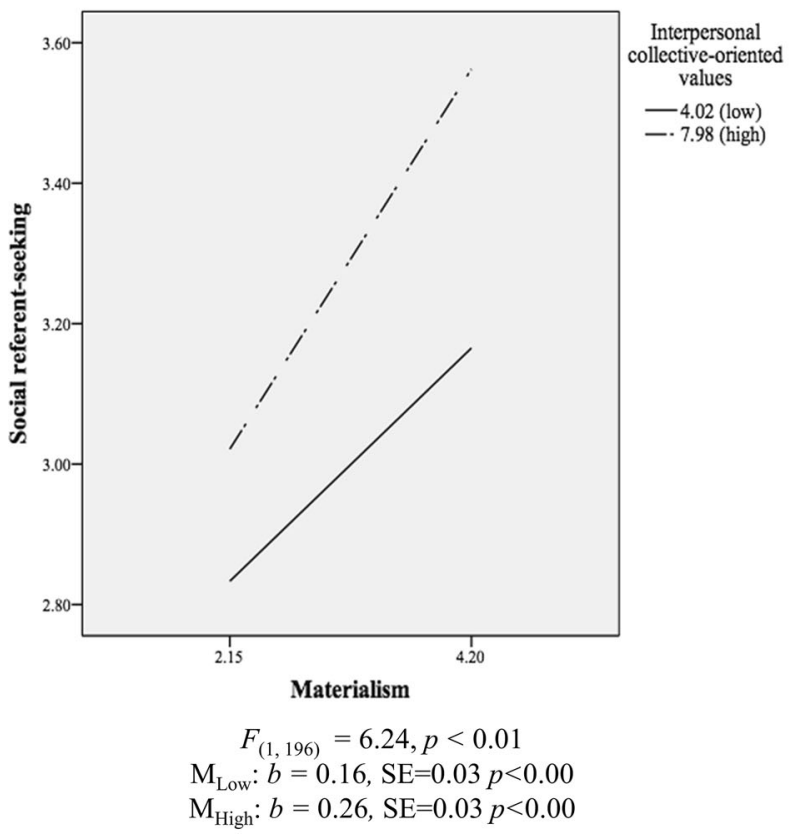

Figure 3 Simple slopes on social referent-seeking among collective materialists.

Thus, in collectivistic cultures, where interpersonal values are salient, participants show a reduced propensity to engage with price and brand referents during conspicuous consumption deliberation, but an increased proclivity to seek social referents. Thus, collective-oriented materialists in Asia (i.e., 
Panel A: Transcendental collective values in $\boldsymbol{U} \boldsymbol{S}$ reduces materialistic pursuit of price referent

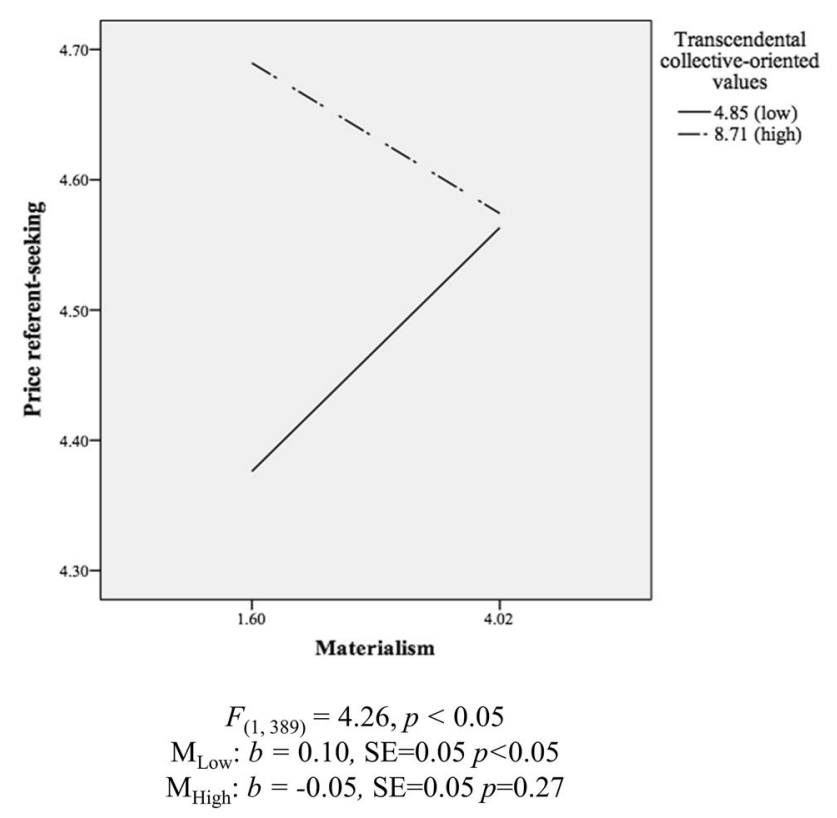

Panel C: Interpersonal collective values in India reduces materialistic pursuit of price referent

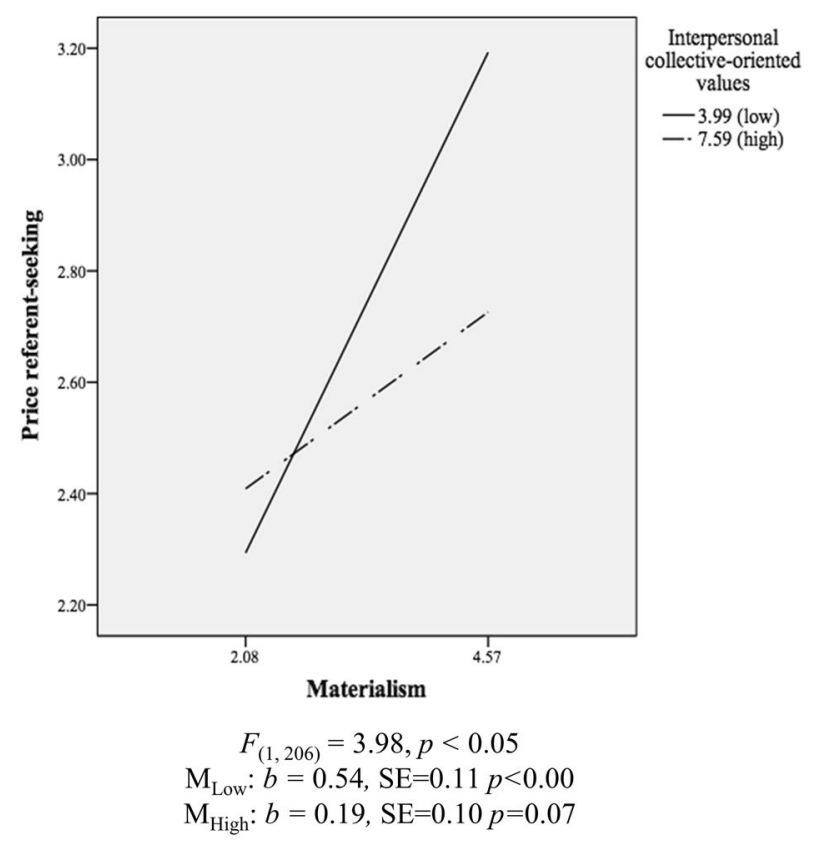

Panel B: Interpersonal collective values in China reduces materialistic pursuit of price referent

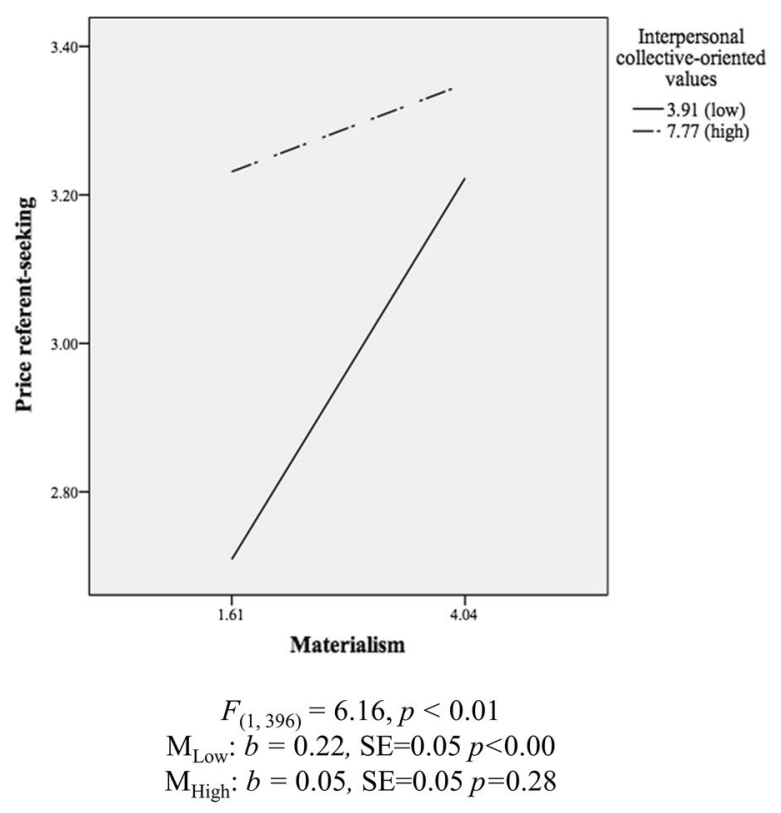

Panel D: Interpersonal collective values in Thailand reduces materialistic pursuit of price referent.

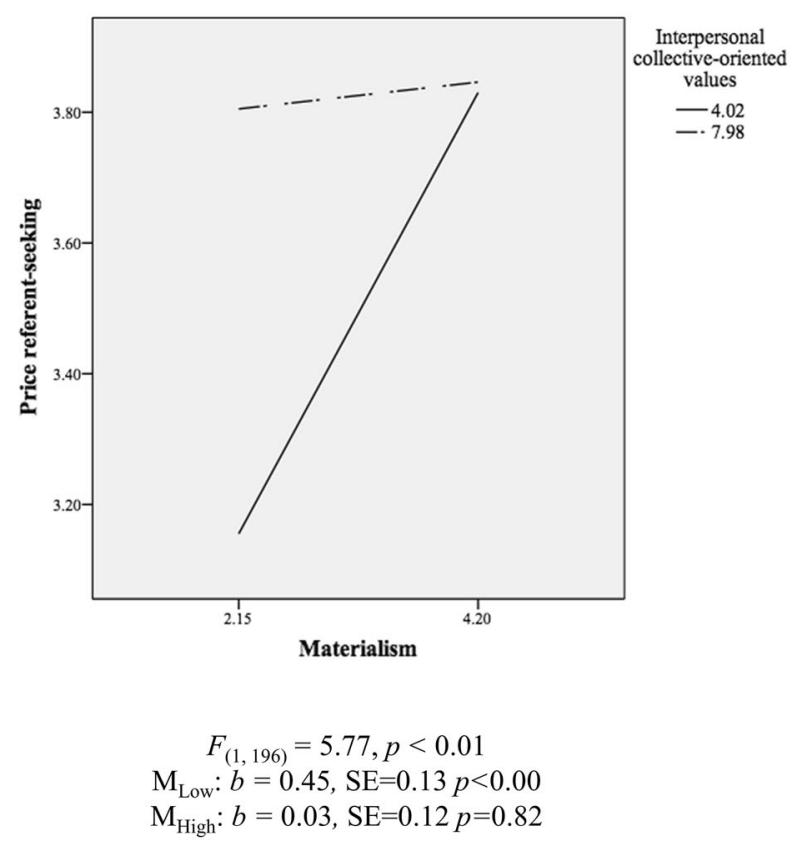

Figure 4 Simple slopes on price referent-seeking among collective materialists.

materialists who also uphold interpersonal collective-oriented values) may very well build a stronger interpersonal relationship by keeping the price and brand elements of their consumptions quiet to reduce the risks of being stigmatized as a superficial and externally motivated materialist. However, in 
Panel A: Transcendental collective values in the $\boldsymbol{U S}$ reduce materialistic pursuit of brand referent-seeking.

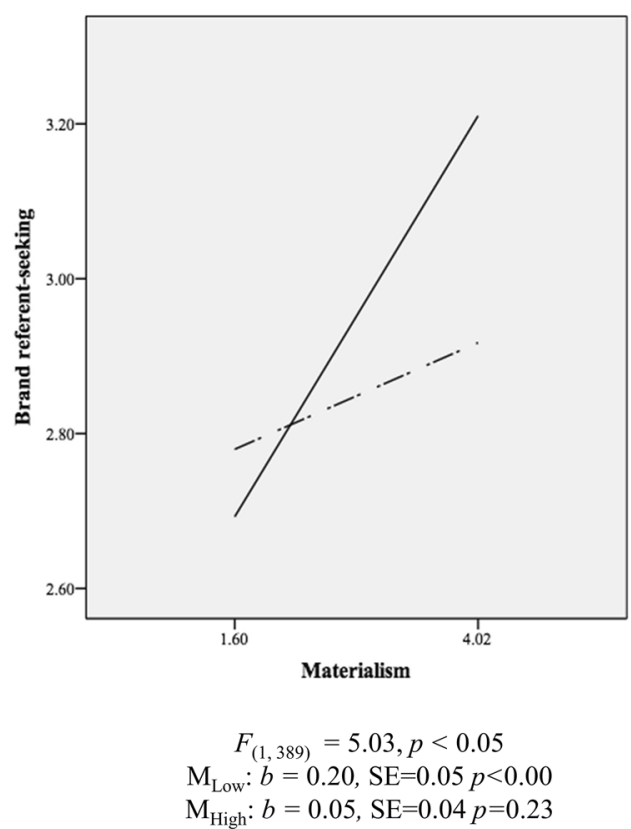

Panel C: Interpersonal collective-oriented values in India reduce materialistic pursuit of brand referent-seeking.

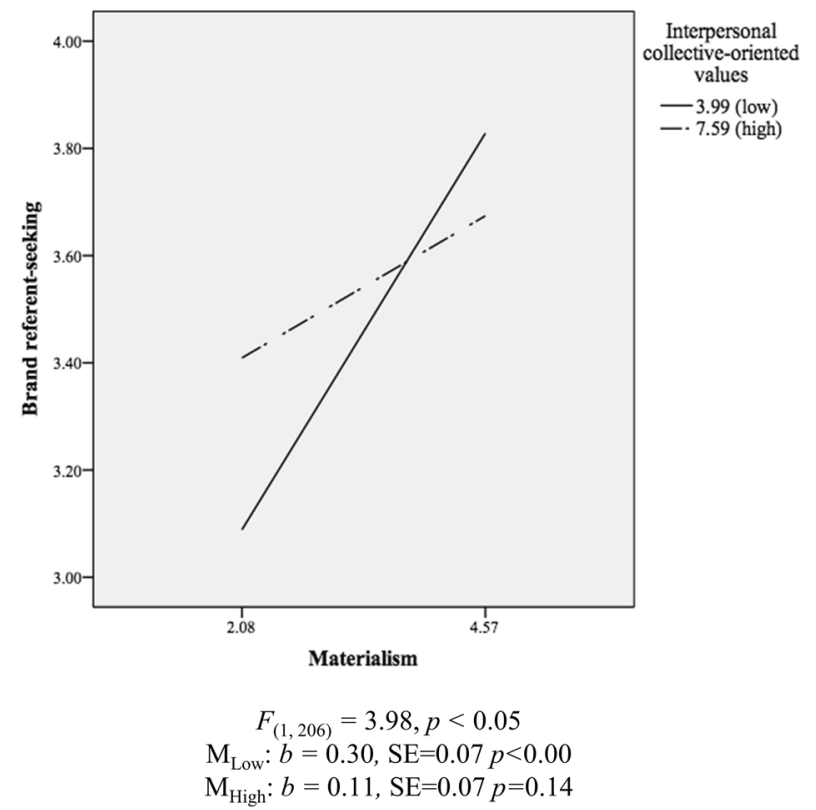

Panel B: Tradition, conformity and security in China reduce materialistic pursuit of brand referent-seeking.

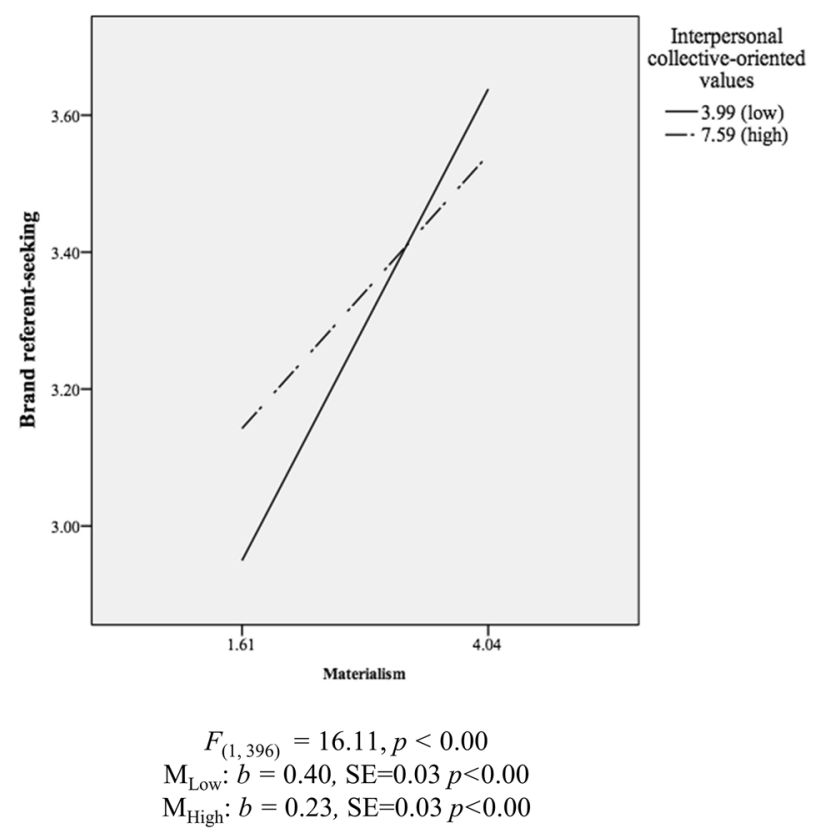

Panel D: Interpersonal collective-oriented values in Thailand reduce materialistic pursuit of brand referentseeking.

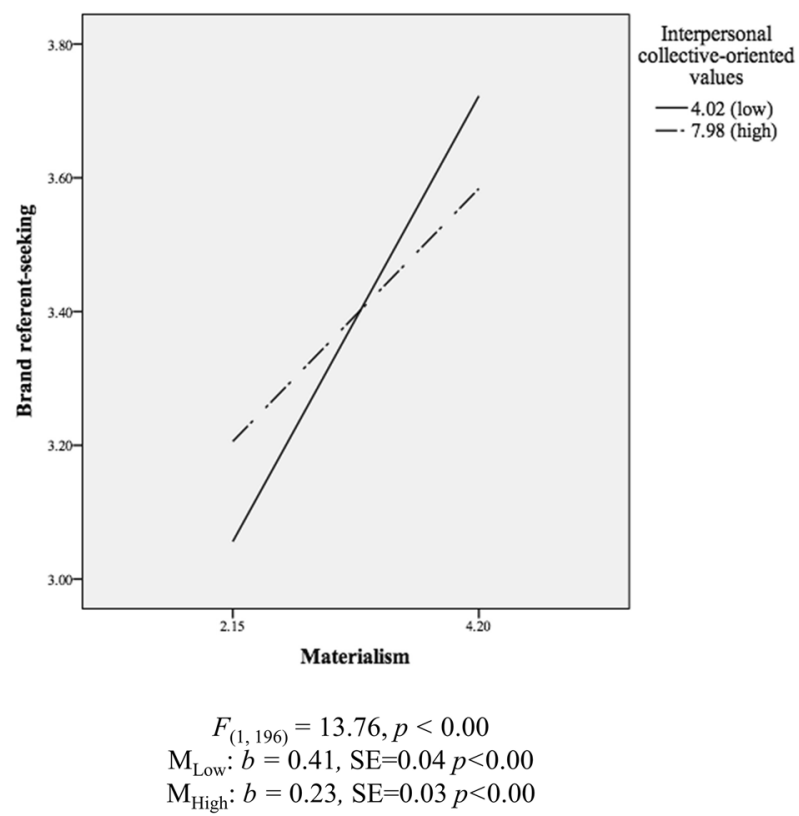

Figure 5 Simple slopes on brand referent-seeking among collective materialists

the US individualistic culture, where transcendental values are salient, people expressed a sweeping reduction in appetite for social-, price-, and brandbased symbolism in conspicuous consumption.
Thus, collective-oriented materialists in the US (i.e., those who subscribe to both material and transcendental collective-oriented values) may prefer to keep away from the public display of 
Table 7 Summary of hypothesis testing

\begin{tabular}{ll}
\hline Hypotheses & Statement \\
\hline $\mathrm{H} 1$ & $\begin{array}{l}\text { In individualistic cultures, materialism is } \\
\text { negatively associated with collective-oriented } \\
\text { values }\end{array}$
\end{tabular}

$\mathrm{H} 2$

In collectivistic cultures, materialism is positively associated with collective-oriented values

$\mathrm{H} 3$

$\mathrm{H} 4 \mathrm{a}$ In individualistic cultures, transcendental collective-oriented values positively moderate the relationship between materialism and social referent-seeking

$\mathrm{H} 4 \mathrm{~b}$ In collectivistic cultures, interpersonal collectiveoriented values positively moderate the relationship between materialism and social referent-seeking

H5 Materialism positively influences price referentseeking

H6a In individualistic cultures, transcendental collective-oriented values negatively moderate the relationship between materialism and price referent-seeking

$\mathrm{H} 6 \mathrm{~b}$ In collectivistic cultures, interpersonal collectiveoriented values negatively moderate the relationship between materialism and price referent-seeking

$\mathrm{H} 7$ Materialism positively influences brand referentseeking

H8a In individualistic cultures, transcendental collective-oriented values negatively moderate the relationship between materialism and brand referent-seeking

$\mathrm{H} 8 \mathrm{~b}$ In collectivistic cultures, interpersonal collectiveoriented values negatively moderate the relationship between materialism and brand referent-seeking
Results

Support of

hypothesis

In US data, materialism negatively correlates to collective-oriented values. MDS analysis suggests that participants observed high conceptual distance between materialism and collective-oriented values

In Chinese, Indian, and Thai data, materialism positively Supported correlates to all collective-oriented values, except for materialism and universalism in China. MDS analysis suggests that participants observed narrow conceptual distance between materialism and collective-oriented values

Materialism positively influences social referent-seeking

$\left(b_{\mathrm{US}}=0.24, p<0.01 ; b_{\text {India }}=0.13, p<0.01\right.$;

$b_{\text {China }}=0.16, p<0.01 ; b_{\text {Thai }}=0.22, p<0.01$ )

TCOV negatively moderates the relationship between materialism and social referent-seeking in the US

$\left(b_{\mathrm{US}}=-0.04, p<0.05\right)$

ICOV positively moderates materialism and social referent-seeking in China $\left(b_{\text {China }}=0.08, p<0.01\right)$, India $\left(b_{\text {India }}=0.04, p<0.05\right)$, and Thailand $\left(b_{\text {Thai }}=0.07, p<0.01\right)$

Materialism positively influences price referent-seeking $\left(b_{\text {US }}=0.12, p<0.01 ; b_{\text {India }}=0.36, p<0.01\right.$;

$b_{\text {China }}=0.35, p<0.01 ; b_{\text {Thai }}=0.24, p<0.01$ )

TCOV negatively moderates the relationship between materialism and price referent-seeking in the US

$\left(b_{\mathrm{US}}=-0.03, p<0.01\right.$ )

ICOV negatively moderates materialism and price referent-seeking in China $\left(b_{\text {China }}=-0.07, p<0.01\right)$, India $\left(b_{\text {India }}=-0.13, p<0.01\right)$, and Thailand $\left(b_{\text {Thai }}=-0.16, p<0.01\right)$

Materialism positively influences brand referent-seeking $\left(b_{\mathrm{US}}=0.12, p<0.01 ; b_{\text {India }}=0.15, p<0.01\right.$;

$b_{\text {China }}=0.32, p<0.01 ; b_{\text {Thai }}=0.32, p<0.01$ )

TCOV negatively moderates the relationship between materialism and brand referent-seeking in the US

$\left(b_{\mathrm{US}}=-0.04, p<0.05\right)$

ICOV negatively moderates materialism and brand referent-seeking in China $\left(b_{\text {China }}=-0.05, p<0.01\right)$, India $\left(b_{\text {India }}=-0.05, p<0.05\right)$, and Thailand $\left(b_{\text {Thai }}=-0.05, p<0.01\right)$

Supported

Supported

Not

supported

Supported

Supported

Supported

Supported

Supported

Supported

Supported

consensus that consumers across the globe are becoming more materialistic in the same manner and style (Ger \& Belk, 1996; Sharma, 2011). Extant literature shows that the combination of Westerncontrolled mass marketing and the natural desire of humans to improve their lives materially work in forces to compel consumers worldwide to emulate those in the developed West (Cleveland et al., 2009). However, the predominant view of self- 
oriented materialism may be too simplistic in conceptualizing materialistic consumption that stems from collective-oriented motivations. Our research makes a theoretical and empirical contribution to international consumer research by expanding the boundary of materialism to include collective-oriented materialism. In advancing the cultural divergence hypothesis (de Mooij \& Hofstede, 2002; Douglas \& Craig, 2011), we demonstrate that the predominant view of self-oriented materialism is not entirely generalizable to collectivist and individualist consumers who espouse collectiveoriented values.

Despite the prevalence of self-centered materialism in modern consumer society, our framework shows that activating the normative collective ideals among materialists may be an effective strategy for promoting collective-oriented materialism. Our findings show that collective-oriented materialists in China, India, and Thailand actively respond to interpersonal collective ideals by increasing social referent-seeking and reducing price and brand referent-seeking activities. These consumers may be willing to purchase more expensive and less ostentatious brands in favor of purchases that foster social acceptance and communicate the prosocial reputation of the consumer. Thus, global businesses and non-profits are well advised to promote their offerings in a way that clearly demonstrates the consumers' duty and commitment to their social group. For example, marketing promotions may advocate interpersonal ties (e.g., filial piety) or employ visible marks (e.g., the red-colored range of products licensed by $\left(\right.$ PRODUCT) ${ }^{\mathrm{RED} \otimes}$ to symbolize charity donation to the Global AIDS funds) that customers can publicly display to showcase their collective-oriented values while enhancing their social status.

Such a strategy, however, may yield variable results across cultures. Note that in our study the normative and salient interpretation of the collective varies across individualistic and collectivistic cultures. In the United States, where transcendental collective values are the norm, consumers respond better to the abstract and spiritual, rather than the interpersonal ideals of the collective. Furthermore, these consumers respond by lessening social, price, and brand referent-seeking activities. Thus, global marketers and policymakers who wish to tap into collective-oriented materialism in individualistic societies may be well advised to promote the private incentives and rewards of prosocial consumption (e.g., tax rebate, cashback, personal challenge such as the social media campaign on ALS "ice bucket challenge"), which consumers can use to reaffirm their collective identity, instead of promoting conspicuous consumption.

Importantly, the present study speaks to the ongoing academic interest to promote prosocial consumption in an increasingly materialistic society (Griskevicius, Tybur, \& Van den Bergh, 2010; Muethel, Hoegl, \& Parboteeah, 2011; Stephan, Uhlaner, \& Stride, 2015). This study offers an opportunity for a collaborative effort by global businesses, NGOs, and policy developers to promote collective-oriented materialism. Such a commitment, however, requires conscious engagement in marketing activities designed to elicit conformance to collective norms that are mutually beneficial to the individual and collective interests (Burroughs \& Rindfleisch, 2012), such as in the case of multi-industry and policy collaboration to entice greater prosocial consumption.

\section{LIMITATIONS AND FUTURE RESEARCH}

Our study must, of course, be interpreted in light of its limitations. We hypothesized and demonstrated that the alignment between materialism and collective-oriented values is influenced by cultural differences in the normative interpretation of the collective. However, some words of caution are necessary. Our data did not highlight differences in ethnicities and subcultures, which may lead to an underestimation of intracultural differences. Nonetheless, we have reasons to remain confident in our findings. The present research offers support for collective-oriented materialism, which arises from the dominant view of the collective across individualistic and collectivistic cultures. This suggests that materialism is more nuanced and culturally dependent than it has been previously portrayed in academia and practice. Nonetheless, future research may extend the reach of collectiveoriented materialism on other ethnic groups (e.g., Chinese diaspora in the US) to examine its generalizability across subcultures. Other research may also investigate the influence of various cultural dynamics in shaping materialism, such as power distance and masculinity/femininity (Hofstede, 2001). Further research can also examine the dynamism of collective-oriented materialism over time and across cultures. Indeed, the US consumers' view of possessions and acquisitions today certainly differs than the view of consumers in the mid1980s. Similarly, the materialistic views of Asian 
consumers may evolve along with the advancements of technology, social entrepreneurship, and emerging markets.

From a methodological perspective, the measure of referent-seeking inclination may not fully capture real referent-seeking behaviors. Hence, future research may solidify the collective-oriented facet of materialism through controlled behavioral experimental in the field or laboratory settings. Moreover, our snowball sampling approach may limit the generalizability and representativeness of the findings. Thus, a future replication on a random sample may be necessary to reduce the sampling biases associated with such convenience sampling techniques.

One vexing question that corporations face in recent times is how to get consumers to engage in more prosocial spending (e.g., charity donation, buying socially responsible goods and services) to

\section{REFERENCES}

Abela, A. V., \& Murphy, P. E. 2007. Marketing with integrity: Ethics and the service-dominant logic for marketing. Journal of the Academy of Marketing Science, 36(1): 39-53.

Aggarwal, P., \& McGill, A. L. 2012. When brands seem human, do humans act like brands? Automatic behavioral priming effects of brand anthropomorphism. Journal of Consumer Research, 39(2): 307-323.

Ahuvia, A. C., \& Wong, N. Y. C. 1995. Materialism: origins and implications for personal well-being. Association for Consumer Research, 172-178.

Ahuvia, A. C., \& Wong, N. Y. C. 2002. Personality and values based materialism: Their relationship and origins. Journal of Consumer Psychology, 12(4): 389-402.

Aiken, L. S., West, S. G., \& Reno, R. R. 1991. Multiple regression: Testing and interpreting interactions. Newbury Park, CA: Sage.

Aknin, L. B., Barrington-leigh, C. P., Dunn, E. W., Helliwell, J. F., Burns, J., \& Biswas-diener, R., et al. 2013. Prosocial spending and well-being: Cross-cultural evidence for a psychological universal. Journal of Personality and Social Psychology, 104(4): 632-652.

Amaldoss, W., \& Jain, S. 2005. Conspicuous consumption and sophisticated thinking. Management Science, 51(10): 1449-1466.

Anderson, J. C., \& Gerbing, D. W. 1988. Structural equation modeling in practice: A review and recommended two-step approach. Psychological Bulletin, 103(3): 411-423.

Bagozzi, R. P., Wong, N., \& Yi, Y. 1999. The role of culture and gender in the relationship between positive and negative affect. Cognition and Emotion, 13(6): 641-672.

Bao, Y., Zhou, K. Z., \& Su, C. 2003. Face consciousness and risk aversion: Do they affect consumer decision-making? Psychology and Marketing, 20(8): 733-755.

Batra, R., Ramaswamy, V., Alden, D., Steenkamp, J., \& Ramachander, S. 2000. Effects of brand local and nonlocal origin on consumer attitudes in developing countries. Journal of Consumer Psychology, 9(2): 83-95.

Bauer, M. A., Wilkie, J. E. B., Kim, J. K., \& Bodenhausen, G. V. 2012. Cuing consumerism: Situational materialism undermines personal and social well-being. Psychological Science, 23(5): 517-523. improve well-being across the value chain (Aknin et al., 2013; Bock, Eastman, \& Eastman, 2016). Global corporations also face calls to address the environmental consequences resulting from mass production for materialistic consumption (Abela \& Murphy, 2007; Kasser, 2016). Indeed, multinationals possess both the resources and transformative capacity (Mick, Pettigrew, Pechmann, \& Ozanne, 2012; Porter \& Kramer, 2011) to embed greater prosocial values within the consumer culture and build a socially conscious image of global business. Our findings offer a crucial first step in showing that materialistic consumption can be geared towards collective interest that benefits individual consumers and the wider society. Future research should therefore broaden the practicality of collective-oriented materialism across various contexts of prosocial consumption and explore the boundary conditions surrounding its application.

Baumeister, R. F., \& Leary, M. R. 1995. The need to belong: Desire for interpersonal attachments as a fundamental human motivation. Psychological Bulletin, 117(3): 497-529.

Bearden, W. O., \& Etzel, J. 1982. Reference group influence on product and brand purchase decisions. Journal of Consumer Research, 9(2): 183-194.

Belk, R. W. 1985. Materialism: Trait aspects of living in the material world. Journal of Consumer Research, 12(3): 265-280.

Belk, R. W. 1988. Possessions and the extended self. Journal of Consumer Research, 15(2): 139-168.

Belk, R. W., \& Pollay, R. W. 1985. Images of ourselves: The good life in twentieth century advertising. Journal of Consumer Research, 11(4): 887-897.

Beugelsdijk, S., Kostova, T., \& Roth, K. 2016. An overview of Hofstede-inspired country-level culture research in international business since 2006. Journal of International Business Studies, 48(1): 30-47.

Blair, E., \& Zinkhan, G. M. 2006. Nonresponse and generalizability in academic research. Journal of the Academy of Marketing Science, 34(1): 4-7.

Bock, D. E., Eastman, J. K., \& Eastman, K. L. 2016. Encouraging Consumer Charitable Behavior: The Impact of Charitable Motivations, Gratitude, and Materialism. Journal of Business Ethics, advance online publication 21 May 2016. doi:10.1007/ s10551-016-3203-x.

Brewer, M. B. 1991. The social self: On being the same and different at the same time. Society for Personality and Social Psychology, 17(5): 475-482.

Brewer, M. B., \& Chen, Y.-R. 2007. Where (Who) are collectives in collectivism? Toward conceptual clarification of individualism and collectivism. Psychological Review, 114(1): 133-151.

Brislin, R. W. 1970. Back-translation for cross-cultural research. Journal of Cross-Cultural Psychology, 1(3): 185-216.

Buhrmester, M., Kwang, T., \& Gosling, S. D. 2011. Amazon's mechanical turk: A new source of inexpensive, yet highquality, data? Perspectives on Psychological Science, 6(1): 3-5.

Burroughs, J. E., Chaplin, L. N., Pandelaere, M., Norton, M. I., Ordabayeva, N., Gunz, A., et al. 2013. Using motivation theory to develop a transformative consumer research agenda for reducing materialism in society. Journal of Public Policy \& Marketing, 32(1): 18-31. 
Burroughs, J. E., \& Rindfleisch, A. 2002. Materialism and wellbeing: A conflicting values perspective. Journal of Consumer Research, 29(3): 348-370.

Burroughs, J. E., \& Rindfleisch, A. 2012. What welfare? On the definition and domain of transformative consumer research and the foundational role of materialism. In D. G. Mick, S. Pettigrew, C. Pechmann, \& J. L. Ozanne (Eds.), Transformative consumer research for personal and collective well-being. New York: Routledge.

Byrne, B. M. 2008. Testing for multigroup equivalence of a measuring instrument: A walk through the process. Psicothema, 20(4): 872-882.

Caprar, D. V., Devinney, T. M., Kirkman, B. L., \& Caligiuri, P. 2015. Conceptualizing and measuring culture in international business and management: From challenges to potential solutions. Journal of International Business Studies, 46(9): 1011-1027.

Chan, H., Wan, L. C., \& Sin, L. Y. M. 2009. The Contrasting effects of culture on consumer tolerance: Interpersonal face and impersonal fate. Journal of Consumer Research, 36(2): 292-304.

Chang, L. C., \& Arkin, R. M. 2002. Materialism as an attempt to cope with uncertainty. Psychology and Marketing, 19(5): 389-406.

Chaplin, L. N., \& John, D. R. 2007. Growing up in a material world: Age differences in materialism in children and adolescents. Journal of Consumer Research, 34(4): 480-493.

Cheung, G. W., \& Rensvold, R. B. 2002. Evaluating goodness-offit indexes for testing measurement invariance. Structural Equation Modeling: A Multidisciplinary Journal, 9(2): 233-255.

Chung, K. Y., Eichenseher, J. W., \& Taniguchi, T. 2007. Ethical perceptions of business students: Differences between East Asia and the USA and among "Confucian" cultures. Journal of Business Ethics, 79(1-2): 121-132.

Cialdini, R. B., \& Goldstein, N. J. 2004. Social influence: Compliance and conformity. Annual Review of Psychology, 55(1974): 591-621.

Cleveland, M. 2015. Wanting things and needing affiliation: Ethnic consumers and materialism. In A. Jamal, L. Peñaloza, \& M. Laroche (Eds.), The Routledge companion to ethnic marketing. New York: Routledge.

Cleveland, M., \& Chang, W. 2009. Migration and materialism: The roles of ethnic identity, religiosity, and generation. Journal of Business Research, 62(10): 963-971.

Cleveland, M., Laroche, M., \& Papadopoulos, N. 2009. Cosmopolitanism, consumer ethnocentrism, and materialism: An eight-country study of antecedents and outcomes. Journal of International Marketing, 17(1): 116-146.

Cohen, J., \& Cohen, P. 1983. Applied multiple regression/correlation analysis for the behavioral sciences. New Jersey: Lawrence Erlbaum Associates.

de Mooij, M., \& Hofstede, G. 2002. Convergence and divergence in consumer behavior: Implications for international retailing. Journal of Retailing, 78(1): 61-69.

Dittmar, H., Bond, R., Hurst, M., \& Kasser, T. 2014. The Relationship between materialism and personal well-being: A meta-analysis. Journal of Personality and Social Psychology, 107(5): 879-924.

Douglas, S. P., \& Craig, C. S. 2011. Convergence and divergence: Developing a semiglobal marketing strategy. Journal of International Marketing, 19(1): 82-101.

Escalas, J. E., \& Bettman, J. R. 2005. Self-construal, reference groups, and brand meaning. Journal of Consumer Research, 32(3): 378-389.

Fournier, S. 1998. Consumers and their brands: Developing relationship theory in consumer research. Journal of Consumer Research, 24(4): 343-353.

Fournier, S., \& Richins, M. L. 1991. Some theoretical and popular notions concerning materialism. Journal of Social Behavior \& Personality, 6(6): 403-414.
Frias, M. T., Shaver, P. R., \& Diaz-Loving, R. 2013. Individualism and collectivism as moderators of the association between attachment insecurities, coping, and social support. Journal of Social and Personal Relationships, 31(1): 3-31.

Ger, G. \& Belk, R. W. 1990. Measuring and comparing materialism cross-culturally. Advances in Consumer Research, 17: 186-193.

Ger, G., \& Belk, R. W. 1996. Cross-cultural differences in materialism. Journal of Economic Psychology, 17: 55-77.

Gierl, H., \& Huettl, V. 2010. Are scarce products always more attractive? The interaction of different types of scarcity signals with products' suitability for conspicuous consumption. International Journal of Research in Marketing, 27(3): 225-235.

Griskevicius, V., Tybur, J. M., Sundie, J. M., Cialdini, R. B., Miller, G. F., \& Kenrick, D. T. 2007. Blatant benevolence and conspicuous consumption: When romantic motives elicit strategic costly signals. Journal of Personality and Social Psychology, 93(1): 85-102.

Griskevicius, V., Tybur, J. M., \& Van den Bergh, B. 2010. Going green to be seen: Status, reputation, and conspicuous conservation. Journal of Personality and Social Psychology, 98(3): 392-404.

Güngör, D., Karasawa, M., Boiger, M., Dinçer, D., \& Mesquita, B. (2014). Fitting in or sticking together: The prevalence and adaptivity of conformity, relatedness, and autonomy in Japan and Turkey. Journal of Cross-Cultural Psychology, 45(9): 1374-1389.

Hamamura, T. 2012. Are cultures becoming individualistic? A cross-temporal comparison of individualism-collectivism in the United States and Japan. Personality and Social Psychology Review, 16(1): 3-24.

Han, Y. J., Nunes, J. C., \& Drèze, X. 2010. Signaling status with luxury goods: The role of brand prominence. Journal of Marketing, 74: 15-30.

Ho, D. Y. 1976. On the concept of face. American Journal of Sociology, 81(4): 867-884.

Hofstede, G. 2001. Culture's consequences: Comparing values, behaviors, institutions and organizations across nations. London: Sage.

Hudders, L., \& Pandelaere, M. 2011. The silver lining of materialism: The impact of luxury consumption on subjective well-being. Journal of Happiness Studies, 13(3): 411-437.

Hult, G. T. M., Ketchen, D. J., Griffith, D. A., Finnegan, C. A., Gonzalez-Padron, T., \& Harmancioglu, N., et al. 2008. Data equivalence in cross-cultural international business research: Assessment and guidelines. Journal of International Business Studies, 39(6): 1027-1044.

Hunt, J. M., Kernan, J. B., \& Mitchell, D. J. 1996. Materialism as social cognition: People, possessions, and perception. Journal of Consumer Psychology, 5(1): 65-83.

Hwang, Y., Ko, E., \& Megehee, C. M. 2014. When higher prices increase sales: How chronic and manipulated desires for conspicuousness and rarity moderate price's impact on choice of luxury brands. Journal of Business Research, 67(9): 1912-1920.

Kasser, T. 2002. The high price of materialism. Cambridge, MA: The MIT Press.

Kasser, T. 2016. Materialistic values and goals. Annual Review of Psychology, 67: 489-514.

Kasser, T., \& Ahuvia, A. 2002. Materialistic values and well-being in business students. European Journal of Social Psychology, 32(1): 137-146.

Kasser, T., \& Ryan, R. M. 1993. A dark side of the American dream: Correlates of financial success as a central life aspiration. Journal of Personality and Social Psychology, 65(2): 410-422.

Kim, H., \& Kramer, T. 2015. Do materialists prefer the "Brandas-Servant"? The interactive effect of anthropomorphized brand roles and materialism on consumer responses. Journal of Consumer Research, 42(2): 284-299. 
Klein, N. M., \& Oglethorpe, J. E. 1984. Cognitive reference points in consumer decision making. Advances in Consumer Research, 14: 183-188.

Kopalle, P. K., Lehmann, D. R., \& Farley, J. U. 2010. Consumer expectations and culture: The effect of belief in karma in India. Journal of Consumer Research, 37(2): 251-263.

Kruskal, J. B. 1964. Multidimensional scaling by optimizing goodness of fit to a nonmetric hypothesis. Psychometrika, 29(1): 1-27.

Lee, J., \& Shrum, L. J. 2012. Conspicuous consumption versus charitable behavior in response to social exclusion: A differential needs explanation. Journal of Consumer Research, 39(3): 530-544.

Leonardelli, G. J., Pickett, C. L., \& Brewer, M. B. 2010. Optimal distinctiveness theory: A framework for social identity, social cognition, and intergroup relations. In M. P. Zanna \& J. M. Olson (Eds.), Advances in experimental social psychology (pp. 63-107). San Diego: Elsevier.

Leung, K., \& Morris, M. W. 2014. Values, schemas, and norms in the culture-behavior nexus: A situated dynamics framework. Journal of International Business Studies, 46(9): 1-23.

Liao, J., \& Wang, L. 2009. Face as a mediator of the relationship between material value and brand consciousness. Psychology and Marketing, 26(11): 987-1001.

Lindeman, M., \& Verkasalo, M. 2005. Measuring values with the short Schwartz's value survey. Journal of Personality Assessment, 85(2): 170-178.

Lynn, M. 1991. Scarcity effects on value: A quantitative review of the commodity theory literature. Psychology and Marketing, 8(1): 43-57.

Markus, H. R., \& Kitayama, S. (1991). Culture and the self: Implications for cognition, emotion, and motivation. Psychological Review, 98(2), 224-253.

McDonald, R. P. 1989. An index of goodness-of-fit based on noncentrality. Journal of Classification, 6(1): 97-103.

Mick, D. G. 1996. Are studies of dark side variables confounded by socially desirable responding? The case of materialism. Journal of Consumer Research, 23(2): 106-119.

Mick, D. G., Pettigrew, S., Pechmann, C., \& Ozanne, J. L. 2012. Transformative consumer research-for personal and collective well-being. London: Routledge.

Monroe, K. B. 1973. Buyers' subjective perceptions of price. Journal of Marketing Research, 10(1): 70-80.

Muethel, M., Hoegl, M., \& Parboteeah, K. P. 2011. National business ideology and employees' prosocial values. Journal of International Business Studies, 42(2): 183-201.

Mullen, M. R. 1995. Diagnosing measurement equivalence in cross-national research. Journal of International Business Studies, 26(3): 573-596.

Muthén, B., \& Muthén, L. K. 2013. Mplus Version 7.11.

Nielsen. 2014. Global Consumers Are Willing to Put Their Money Where Their Heart Is. http://www.nielsen.com/us/en/pressroom/2014/global-consumers-are-willing-to-put-their-moneywhere-their-heart-is.html.

Oyserman, D., Coon, H. M., \& Kemmelmeier, M. 2002. Rethinking individualism and collectivism: Evaluation of theoretical assumptions and meta-analyses. Psychological Bulletin, 128(1): 3-72.

Pace, S. 2013. Does religion affect the materialism of consumers? An empirical investigation of buddhist ethics and the resistance of the self. Journal of Business Ethics, 112(1): 25-46.

Park, S. Y. 1998. A comparison of Korean and American giftgiving behaviors. Psychology \& Marketing, 15(6): 577-593.

Peng, K., \& Nisbett, R. E. (1999). Culture, dialectics, and reasoning about contradiction. American Psychologist, 54(9), 741-754.

Peterson, M. F., Søndergaard, M., \& Kara, A. 2017. Traversing cultural boundaries in IB: The complex relationships between explicit country and implicit cultural group boundaries at multiple levels. Journal of International Business Studies.

Pew Research. 2014. Teaching the children: Sharp ideological differences, some common ground.
Pieters, R. 2013. Bidirectional dynamics of materialism and loneliness: Not just a vicious cycle. Journal of Consumer Research, 40(4): 615-631.

Porter, M. E., \& Kramer, M. R. 2011. Creating shared value. Harvard Business Review, 89(1/2): 62-77.

Puntoni, S., \& Tavassoli, N. T. 2007. Social context and advertising memory. Journal of Marketing Research, 44(2): 284-296.

Richins, M. L. 2004. The material values scale: Measurement properties and development of a short form.Journal of Consumer Research, 31(1): 209-219.

Richins, M. L. 2011. Materialism, transformation expectations, and spending: Implications for credit use. Journal of Public Policy \& Marketing, 30(2): 141-156.

Richins, M. L., \& Chaplin, L. N. 2015. Material parenting: How the use of goods in parenting fosters materialism in the next generation. Journal of Consumer Research, 41(6): 1333-1357.

Richins, M. L., \& Dawson, S. 1992. A consumer values orientation for materialism and its measurement: Scale development and validation. Journal of Consumer Research, 19(3): 303-316.

Rindfleisch, A., Burroughs, J. E., \& Wong, N. Y. C. 2009. The safety of objects: Materialism, existential insecurity, and brand connection. Journal of Consumer Research, 36(1): 1-16.

Ronen, S., \& Shenkar, O. 2013. Mapping world cultures: Cluster formation, sources and implications. Journal of International Business Studies, 44(9): 867-897.

Rose, G. M., Dalakas, V., \& Kropp, F. 2003. Consumer socialization and parental style across cultures: Findings from Australia, Greece, and India. Journal of Consumer Psychology, 13(4): 366-376.

Ruvio, A. 2008. Unique like everybody else? The dual role of consumers' need for uniqueness. Psychology and Marketing, 25(5): 444-464.

Ryan, M. J. 1982. Behavioral intention formation: The interdependency of attitudinal and social influence variables. Journal of Consumer Research, 9(3): 263-278.

Schwartz, S. H. 1990. Individualism-collectivism: Critique and proposed refinements. Journal of Cross-Cultural Psychology, 21(2): 139-157.

Schwartz, S. H. 1992. Universals in the content and structure of values: Theoretical advances and empirical tests in 20 countries. Advances in Experimental Social Psychology, 25(1): 1-65.

Schwartz, S. H. 2006. A theory of cultural value orientations: Explication and applications. Comparative Sociology, 5(2): 137-182.

Schwartz, S. H., Melech, G., Lehmann, A., Burgess, S., Harris, M., \& Owens, V. 2001. Extending the cross-cultural validity of the theory of basic human values with a different method of measurement. Journal of Cross-Cultural Psychology, 32(5): 519-542.

Sharma, P. (2011). Country of origin effects in developed and emerging markets: Exploring the contrasting roles of materialism and value consciousness. Journal of International Business Studies, 42(2): 285-306.

Shrum, L. J.. Lowrey, T. M., Pandelaere, M., Ruvio, A. A., Gentina, E., Furchheim, P. et al. 2014. Materialism: The good, the bad, and the ugly. Journal of Marketing Management, (November): 1-24.

Shrum, L. J., Wong, N. Y. C., Arif, F., Chugani, S. K., Gunz, A., Lowrey, T. M., et al. 2013. Reconceptualizing materialism as identity goal pursuits: Functions, processes, and consequences. Journal of Business Research, 66(8): 1179-1185.

Singelis, T. M. 1994. The measurement of independent and interdependent self-construals. Personality and Social Psychology Bulletin, 20(5): 580-591.

Steenkamp, J. E. M., \& Baumgartner, H. 1998. Assessing measurement invariance in cross-national consumer research. Journal of Consumer Research, 25(1): 78-107.

Steiger, J. H. 1989. EzPATH: Causal modeling. Evanston, IL: SYSTAT. 
Stephan, U., Uhlaner, L. M., \& Stride, C. 2015. Institutions and social entrepreneurship: The role of institutional voids, institutional support, and institutional configurations. Journal of International Business Studies, 46(3): 308-331.

Strizhakova, Y., \& Coulter, R. A. 2013. The "Green" side of materialism in emerging BRIC and developed markets: The moderating role of global cultural identity. International Journal of Research in Marketing, 30(1): 69-82.

Suri, R., Monroe, K. B., \& Koc, U. 2013. Math anxiety and its effects on consumers' preference for price promotion formats. Journal of the Academy of Marketing Science, 41(3): 271-282.

Sweeney, J. C., Soutar, G. N., \& Johnson, L. W. 1999. The role of perceived risk in the quality-value relationship: A study in a retail environment. Journal of Retailing, 75(1): 77-105.

Tatzel, M. 2002. "Money Worlds" and well-being: An integration of money dispositions, materialism and price-related behavior. Journal of Economic Psychology, 23(1): 103-126.

Tian, K. T., Bearden, W. O., \& Hunter, G. L. 2001. Consumers' need for uniqueness: scale development and validation. Journal of Consumer Research, 28(1): 50-66.

Triandis, H. C. 1995. Individualism and collectivism. Boulder, CO: Westview Press.

Triandis, H. C., Bontempo, R., Villareal, M. J., \& Asai, M. 1988. Individualism and collectivism: Cross-cultural perspectives on self-ingroup relationship. Journal of Personality and Social Psychology, 54(2): 323-338.

Triandis, H. C., McCusker, C., \& Hui, C. H. 1990. Multimethod probes of individualism and collectivism. Journal of Personality and Social Psychology, 59(5): 1006-1020.

Van Boven, L., Campbell, M. C., \& Gilovich, T. 2010. Stigmatizing materialism: on stereotypes and impressions of materialistic and experiential pursuits. Personality and Social Psychology Bulletin, 36(4): 551-563.

Veer, E., \& Shankar, A.. 2011. Forgive me, father, for i did not give full justification for my sins: How religious consumers justify the acquisition of material wealth. Journal of Marketing Management, 27(5-6); 547-560.

Verhallen, T. M. M., \& Robben, H. S. J. 1994. Scarcity and preference: An experiment on unavailability and product evaluation. Journal of Economic Psychology, 15(2): 315-331.

Vignoles, V. L., Chryssochoou, X., \& Breakwell, G. M. 2000. The distinctiveness principle: Identity, meaning, and the bounds of cultural relativity. Personality and Social Psychology Review, 4(4): 337-354

Wong, N. Y. C., \& Ahuvia, A. C. 1998. Personal taste and family face: Luxury consumption in confucian and western societies. Psychology and Marketing, 15: 423-441.

Wong, N. Y. C., Rindfleisch, A., \& Burroughs, J. E. 2003. Do reverse-worded items confound measures in cross-cultural consumer research? The case of the material values scale. Journal of Consumer Research, 30(1): 72-91.

Wong, N. Y. C., Shrum, L. J., Arif, F., Chugani, S., Lowrey, T. M., \& Nairn, A., et al. 2011. Rethinking materialism: A process view and some transformative consumer research implications. Journal of Research for Consumers, 19: 7-10.
World Giving Index. 2014. A Global View of Giving Trends. https://www.cafonline.org/PDF/WorldGivinglndex2013_1374 AWEB.pdf.

World Obesity Policy and Prevention. 2008. The Sydney Principles. http://www.worldobesity.org/iotf/obesity/childhoodobesity/ sydneyprinciples/.

\section{ABOUT THE AUTHORS}

Sandra Awanis is a Lecturer in International Marketing at Lancaster University Management School, UK. Her research interest lies in cross-cultural consumer behavior, consumer finance, and automation in consumer decision-making.

Bodo B. Schlegelmilch is Chair of the Institute for International Marketing Management at WU Vienna and holds a Distinguished Research Professorship at Lingnan (University) College, Sun Yatsen University. Previously, he was the Founding Dean of the WU Executive Academy, held professorships in the USA and the UK, and worked for Deutsche Bank and Procter \& Gamble.

Charles Chi Cui is a Senior Lecturer (Associate Professor) at the University of Manchester Alliance Manchester Business School. His research interest is in international marketing strategies and crosscultural behavior. His current work includes consumer brand addiction, social inclusion in marketing, and visual stimuli in global marketing. His interest also expands to critical thinking applied to marketing theory development.

Open Access This article is distributed under the terms of the Creative Commons Attribution 4.0 International License (http://creativecommons.org/ licenses/by/4.0/), which permits unrestricted use, distribution, and reproduction in any medium, provided you give appropriate credit to the original author(s) and the source, provide a link to the Creative Commons license, and indicate if changes were made.

Supplementary information accompanies this article on the Journal of International Business Studies website (www.palgrave-journals.com/jibs). 